\title{
La Cripta de los Mariscales de Navarra en San Pe- dro de la Rúa (Estella). El pleito por la posesión de un espacio privilegiado y la renovación del templo en época moderna ${ }^{1}$.
}

\author{
Ma del Carmen MUÑOZ PÁRRAGA \\ Mª Teresa LÓPEZ DE GUEREÑO SANZ \\ Universidad Autónoma de Madrid
}

Recibido: 15-5-2013 / Aceptado: 27-6-2013

RESUMEN: A mediados del siglo XV la parroquia de San Pedro de la Rúa en Estella (Navarra), importante alto en el camino para los peregrinos que realizaban su viaje a Santiago, experimentará un cambio determinante en su historia. En 1449, Felipe de Navarra, cuarto Mariscal del Reino, y su esposa, Juana de Peralta, eligen el templo de San Pedro como panteón familiar. El presente trabajo se articula en torno a tres perspectivas surgidas de esta circunstancia. La primera se refiere a los cambios arquitectónicos de la cabecera, derivados de la elección como lugar de enterramiento de una de las familias más poderosas en la monarquía navarra. Así, en 1450, se reutilizará uno de los arcos del presbiterio como arcosolio y, en 1552, se construirá en el centro del mismo la cripta, ahora descubierta. La segunda aborda el largo pleito por la posesión de la capilla mayor, originado a partir de 1579 hasta 1678, entre los parroquianos de San Pedro, conscientes de su pérdida de poder, y la familia de los Mariscales, ya Marqueses de Cortes. Finalmente, la tercera tratará de la reforma de la iglesia con el desmonte, en 1609, de la altísima bóveda gótica de la nave central por amenazar ruina, el reforzamiento de los pilares y la colocación de tirantes y, por último, la construcción, en 1731, de la actual bóveda de lunetos, y lo que supuso un considerable decrecimiento de la altura del templo.

Palabras clave: San Pedro de la Rúa, arcosolio, siglo XV, arquitectura moderna, cripta, Mariscales de Navarra, proceso constructivo, siglo XVII, pleito.

ABSTRACT: In mid $15^{\text {th }}$ century the parish church of St. Peter of the Rúa in Estella (Navarre), an important stop on the pilgrims' way to Santiago de Compostela, underwent a decisive change in its history. In 1449, Philip of Navarre, fourth Marshal of the Kingdom, and his wife, Joan of Peralta, chose the temple of St. Peter as their family burial place. The present paper is organised around three perspectives originated from that circumstance. The first perspective refers to the architectural changes in the sanctuary, derived from its choice as the burial place for one of the most powerful families in the Navarrese monarchy. Thus, in 1450, one of the arches in the presbytery was reused as a wall-tomb, and in 1552 the crypt, now discovered, was built in the centre of the presbytery. The second perspective deals with the long lawsuit over the ownership of the major chapel, originated in 1579 going on until 1678, between the parishioners of St. Peter's, well aware of their loss of power, and the family of the Marshals, now Marquises of Cortes. Finally, the third one focuses on the renovation of the church, including the dismantling (in 1609) of the high Gothic vaulted ceiling of the nave because of impending collapse, the reinforcement of the pillars and the placement of tie beams and, at last, the construction (in 1731) of the present lunette vault, which implied a considerable reduction in the height of the temple.

Key words: St. Peter of the Rúa, wall-tomb, $15^{\text {th }}$ century, modern architecture, crypt, Marshals of Navarre, building process, $17^{\text {th }}$ century, lawsuit. 
LOS MARISCALES DE NAVARRA Y SU PANTEÓN FAMILIAR EN SAN PEDRO DE LA RÚA

\section{La primera ubicación del panteón: el arcoso- lio en el lado del Evangelio del presbiterio}

La elección de la parroquia de San Pedro de la Rúa en Estella (Navarra) como lugar de enterramiento de los Mariscales de Navarra, con el tiempo Marqueses de Cortes, tuvo importantes consecuencias para la fábrica del templo. El 23 de marzo de 1449 Felipe de Navarra (1429-1450)², cuarto Mariscal del Reino, y su esposa, Juana de Peralta, disponen en su testamento ser enterrados

\footnotetext{
${ }^{1}$ Este artículo es continuación del estudio de $\mathrm{M}^{\mathrm{a}}$ C. MUÑOZ PÁRRAGA y Mํa T. LÓPEZ DE GUEREÑO SANZ, "Las fábricas medievales de San Pedro de la Rúa en Estella (Navarra): la complejidad de un largo proceso constructivo", De Arte (11), 2012, pp. 27-52. La excavación arqueológica del templo, base fundamental de estos dos trabajos, fue llevada a cabo en 2010 por parte de STRATO, GABINETE DE ESTUDIOS SOBRE PATRIMONIO HISTÓRICO Y ARQUEOLÓGICO, financiada por el Departamento de Cultura y Turismo -Institución Príncipe de Viana del Gobierno de Navarra. El hallazgo de la cripta fue consecuencia del informe previo que las autoras de este artículo realizaron por encargo de STRATO. Véase los resultados de dicha excavación en J. GARCÍA GAZÓLAZ, M.A. MARTÍN CARBAJO et alii, "La iglesia de San Pedro de la Rúa de Estella (Navarra). Intervención arqueológica integral", Trabajos de Arqueología Navarra, no 23, 2011, pp. 175-274 y J. GARCÍA GAZÓLAZ, M.A. MARTÍN CARBAJO y E. FERNÁNDEZ ORALLO, "Intervención arqueológica" en $\mathrm{M}^{\mathrm{a}} \mathrm{R}$. LAZCANO MARTÍNEZ DE MORENTÍN (Coord.), San Pedro de la Rúa de Estella, Pamplona, 2012, pp. 12-51.

Como ya hicimos en el anterior trabajo, desde estas líneas queremos agradecer las atenciones recibidas por la Duquesa de Villahermosa en nuestra visita a su archivo de Pedrola (Zaragoza). Lamentablemente, los documentos citados por Goñi Gaztambide, tras la consulta del archivo cuando éste se encontraba en Madrid, no coinciden con las actuales signaturas. Este hecho nos ha obligado a dar por buenas sus notas, sin haber tenido posibilidad de cotejarlas con los documentos originales.

2 Hijo natural de Leonel de Navarra y, a su vez, hermano natural del rey Carlos III el Noble. El matrimonio entre Felipe y Juana se celebró en 1424, figurando Felipe, a partir de dicho año, como Mariscal del Reino (J. MARTÍNEZ DE AGUIRRE y F. MENÉNDEZ PIDAL, Emblemas heráldicos en el arte medieval navarro, Pamplona, 1996, p. 145).
}

en San Pedro de la Rúa para lo que fundan, además, unas capellanías servidas por cinco capellanes ${ }^{3}$ :

“En el año 1449 el marichal don Phelipe de Navarra y doña Juana de Peralta su mujer en su testamento de hermandad en el primero o segundo capitulo o claussula de el dizen y disponen que cada y cuando Dios ordenare de nosotros que ayamos de morir seamos sepultados dentro de la yglessia maior parrochial del señor San Pedro de la villa de Estella en la endrezera o lugar que el sobreviviente de la cualquiera de nos en el qual dicho lugar será fabricada y fecha de nuevo una sepultura a bien vista y ordinación del dicho sobreviviente de los dos (...) pidiendo sepultura y lugar y sitio para ella en la dicha iglesia y los parrochianos se la concedieron señalándoles el pilar o pared que ay entre la capilla maior y la de la Madre de Dios..."

A finales de la Edad Media, como continuación de la tradición mantenida durante el románico y el gótico, fue habitual que el presbiterio del templo se considerara zona reservada como lugar de enterramiento para personajes de alta posición social o religiosa. Así, en la ordenación del espacio cultual interior se produce necesariamente una importante reorganización, pues se rompe la focalidad única del conjunto del presbiterio.

${ }^{3}$ J. GOÑI GAZTAMBIDE, “La parroquia de San Pedro de la Rúa, de Estella: Historia y Arte", XII Semana de Estudios Medievales 1974, Pamplona, 1976, pp. 161-179, especialmente, p. 169; Id., Historia Eclesiástica de Estella Tomo I. Parroquias, iglesias, capillas reales, Pamplona, 1994, pp. 109-111.

4 "Pleito de la Parroquia de San Pedro de la Rúa contra los Marqueses de Cortes sobre la propiedad de la Capilla Mayor (1579-1678), Articulado de disculpa de los mayordomos, diputados y parroquianos de la iglesia mayor de San Pedro contra Pedro Fernández de Velasco gobernador del estado de Cortes, Año 1579", Archivo Parroquial de San Pedro de la Rúa de Estella, Caja 020, Fajo 4⿳⺈, 38, fol. 1r (hay copia en el Archivo Duques de Villahermosa). Toda la documentación del Archivo Parroquial de San Pedro de la Rúa se encuentra en la actualidad depositada en el Archivo Diocesano de Pamplona. 
De hecho, los presbiterios de algunos templos se convirtieron en verdaderos panteones familiares, como en San Francisco de Guadalajara, para los Mendoza, o en Santa Clara de Palencia, para los Enríquez. Las cabeceras de estas iglesias serán consideradas espacio patrimonial de una familia determinada llegándose, incluso, ante la abundancia de sepulcros de los parientes, a dudar a la hora de indicar el espacio concreto de sepultura, sobreentendiendo que el conjunto del templo podía considerarse como algo propio 5 .

San Pedro de la Rúa no escapa a estos usos y, por ello, no fue casual la ubicación del sepulcro de los Mariscales en el ábside central, reutilizando como arcosolio el hueco de comunicación entre la capilla mayor y la dedicada a la Madre de Dios (Figs. 1 y 2) . $^{6}$ Además, al colocar la sepultura de Felipe de Navarra junto al sagrario de la capilla mayor, en un lugar privilegiado del presbiterio -en el lado del Evangelio del mismo-, se produjo una clara intencionalidad sacra ${ }^{7}$.

Este hecho quedará reflejado durante el pleito que en época moderna enfrentará a la parroquia de San Pedro y a los

\footnotetext{
${ }^{5}$ Para todo lo referente a los enterramientos privilegiados en la Edad Media hispana y la conquista de los espacios más significativos en el interior de las iglesias con el fin de enfatizar el prestigio de los allí enterrados, véase I.G. BANGO TORVISO, “El espacio para enterramientos privilegiados en la arquitectura medieval española", Anuario del Departamento de Historia y Teoría del Arte (U.A.M.), 1992, Vol. IV, pp. 93-132, especialmente, pp. 117-119. Para los enterramientos de San Pedro de la Rúa y su relación con el proceso crono-constructivo de la iglesia medieval, véase $M^{a} \mathrm{C}$. MUÑOZ PÁRRAGA y $M^{a}$ T. LÓPEZ DE GUEREÑO SANZ, "Las fábricas medievales...".

${ }^{6}$ Las recientes excavaciones han descubierto algunos restos óseos poco significativos al levantar las gradas y el pavimento de factura reciente.

${ }^{7}$ A lo largo del siglo XV el sagrario estaba en el lado de la Epístola; seguramente, a finales de este siglo se traslada al lado del Evangelio (AIZPÚN BOBADILLA, "Ubicación de los enterramientos y el sagrario. El caso de Estella (Siglos XV y XVI)", Príncipe de Viana, 2003, Año 64, no 228, pp. 91-126, especialmente, p. 107).
}

Mariscales de Navarra por la propiedad de la capilla mayor, en el que nos detendremos más adelante. En 1579, los parroquianos recuerdan las condiciones según las cuales se cedió gratuitamente el uso del citado arcosolio: “... Yten que siendo esto ansi abra setenta años poco mas o menos que los perroquianos della dieron, graciosamente y sin interés ninguno al marichal don pedro de navarra que murió en Simancas y a su mujer doña mayor de la cueba padres que fueron del primer marques de cortes un Enterramiento En la dicha yglesia en un arco y gueco que esta entre la capilla de nuestra señora y dela capilla mayor. El qual arco esta abierto $y$ tiene bentanas a entrambas las capillas y en el hueco y medio del Esta la sepultura que los parroquianos al dicho marichal dieron que será asi ocho pies de largo y cinco, o, seys de ancho y para señal que esta era su sepultura encima della y del dicho arco a Entrambas partes En las dichas dos capillas les dexaron los dichos parroquianos alos dichos marichales poner sus armas de marido y muger en quatro piedras pequeñas que las dos estan en la capilla mayor y las otras dos en la capilla de nuestra señora teniendo en medio El dicho arco y sepultura correspondiendo las unas armas a las otras las quales claramente significan tener tan solamente derecho al dicho arco y sepultura y no a otra ninguna cossa de las dichas dos capillas sino solamente alo que y abraçan esta en medio de las dichas armas..." ${ }^{8}$.

El sepulcro está formado por un arco apuntado que voltea sobre finas columnillas con capiteles vegetales, trasdosado por una chambrana, también en arco apuntado, que apoya sobre ménsulas encapiteladas vegetales. En el intradós hay una serie de arcos trifoliados con cardinas pinjantes,

\footnotetext{
${ }^{8} \mathrm{Al}$ margen: "la dicha sepultura tiene la entrada y abertura para enterrar los muertos a la parte dela capilla de nuestra señora donde estan unas aldabas de fierro y ninguna cosa ala parte de la capilla mayor" ("Pleito de la Parroquia de San Pedro de la Rúa..., Articulado Antiguo dela Parroquia Contra el Marques de Cortes...", Archivo Parroquial de San Pedro de la Rúa de Estella, Caja 020, Fajo $4^{\circ}$, nº 5).
} 
diseño similar al que podemos ver en la "Galería del rey" del Palacio de Olite. En las enjutas del arco se tallaron sendos escudos, ya sin la policromía original; presentan un diseño con enmarque mixtilíneo formado por un cuadrado lobulado rematado en las esquinas con soluciones vegetales. El de la izquierda pertenece a la familia de los Peralta y muestra un grifo con manteladura corta de Navarra y bordura en aspas; el de la derecha, es el de los Mariscales de Navarra -que tuvo diversas variantes- ostenta dos leones y jefe cargado con medio carbunco de Navarra (Fig. 3) ${ }^{9}$.

Además de Felipe y Juana, en el arcosolio también fueron enterrados varios de sus descendientes: su hijo, Pedro de Navarra (1450-1471), quinto Mariscal y su nieto Felipe de Navarra (1471-1480), que ostentó el título de sexto Mariscal, sepultado primeramente en el monasterio de La Oliva y después trasladado a esta sepultura por su hermano don Pedro de Navarra, quien le sucedió como séptimo Mariscal (1480-1522) ${ }^{10}$. Finalmente, en 1523, se inhumaron en San Pedro los restos de éste quien, en vida, había ampliado la dotación de las capellanías, erigiendo dos altares, nuevamente con licencia del ordinario, y cambiando de sitio otros tres a su costa ${ }^{11}$.

\footnotetext{
${ }_{9}^{9}$ Para su realización se utilizaron elementos habituales en contextos funerarios navarros durante la primera mitad del siglo XIV. La presencia en el sepulcro de San Pedro de capiteles de flora enroscada hace pensar en una cronología más avanzada, a partir de la llegada de Jehan de Lome, en la segunda década de la centuria. Por la notable calidad de los animales representados en los escudos es posible, incluso, que alguien de su taller participara en la realización (J. MARTÍNEZ DE AGUIRRE y F. MENÉNDEZ PIDAL, Emblemas heráldicos.., pp. 144-145).

${ }^{10}$ Archivo Duques de Villahermosa, Estado Cortes, leg. 7, G, 12 y 13, tomado de J. GOÑI GAZTAMBIDE, Historia Eclesiástica de Estella..., p. 110.

11 Falleció en Simancas (Valladolid) el 24 de noviembre de 1522. Su cuerpo recibió sepultura, primero, en el convento franciscano de Abrojo (Valladolid) y, después, en la capilla mayor de San Pedro (Archivo Duques de Villahermosa, Estado Cortes, leg. 7, G, orig. y leg. 9, I, fol. 445, tomado de J. GOÑI GAZTAMBIDE, Historia Eclesiástica de Estella..., p. 110). Sobre la figura
}

El citado pleito entre marqueses y parroquianos ocasionará gran desconcierto en lo que respecta a estos enterramientos pues, en función de sus respectivos intereses, cada una de las partes argumentará el uso del sepulcro según su conveniencia. Atendiendo a la confusa documentación, algunos autores ${ }^{12}$ creen que es posible que el enterramiento no fuera utilizado hasta principios del siglo XVI, ya que en ella se recoge cómo Pedro de Navarra, séptimo Mariscal, hacia 1509 “... acordó de traer como traxo puede haber como setenta años los huessos de sus antepasados que estaban en el monasterio de la Oliva..." y ordenó “...hazer sepulcro para si y sus descendientes, hizo abrir mas una ventana que se debía hazer en el paño y lienço de la pared hazia la parte del Ebangelio como esta agora a la parte de la Epistola otra, que divide la dicha capilla mayor parroquial de la capilla de Nuestra señora y en la misma pared de piedra en lo baxo hizo el dicho su sepulcro o carnario y unas lapidas con aldabas para el servicio de dicho sepulcro dos escudos el uno a un lado y el otro al otro en que están unas cadenas por devisa y debaxo de aquellas dos leones en pie que deben ser las armas de los Enríquez y las armas de Peralta y de los de la Cueva y de la otra parte que cae a la dicha capilla mayor otros dos escudos sin aldabas con las mismas armas el qual sepulcro y obra del esta fresca y como reçien obrada en respecto y comparación de toda la demás obra de la dicha capilla mayor parroquial"13. En otro

de Pedro de Navarra, véase OSTOLAZA ELIZONDO, Ma Isabel, “Las desventuras del mariscal de Navarra: el libro como solaz y paliativo anímico en casos de privación de libertad", Príncipe de Viana, "Estudios sobre el patrimonio cultural y las artes en Navarra en torno a tres hitos 1212-1512-1812", R. FERNÁNDEZ GRACIA (coord.), nº 256 (2012), pp. 565-585.

12 J. AIZPÚN BOBADILLA, “Ubicación de los enterramientos y el sagrario...", p. 103.

13 "Pleito de la Parroquia de San Pedro de la Rúa..., Articulado de disculpa de los mayordomos, diputados y parroquianos de la iglesia mayor de San Pedro contra Pedro Fernández de Velasco gobernador del estado de Cortes, Año 1579", Archivo Parroquial de San Pedro de la Rúa de Estella, Caja 020, Fajo 4º, 38, fol. 2v-3r. 
capítulo del pleito también se recoge que “... el dicho marichal don Pedro fue el primero marichal que se enterro en la dicha capilla mayor de San Pedro donde estaba la dicha su mujer dona Mayor, que esto fue el año de 1523..."14. Abundando en esta misma opinión de retrasar la apertura del arcosolio, en 1579, son los propios parroquianos los que creen erróneamente que fue "don Pedro de Navarra, padre del mariscal del mismo nombre, que murió en Simancas, quien escogió la iglesia para panteón de su familia y abrió la pared para hacer el sepulcro; después comenzaron a enterrarse en medio de la capilla estorbando las funciones" ${ }^{\prime 15}$.

A la vista de los datos, es evidente la confusión que existe en los documentos entre el primer enterramiento, el de Felipe de Navarra, el traslado definitivo a San Pedro de la Rúa de los restos del séptimo Mariscal y el entierro del octavo, a la sazón, padre e hijo que llevaban el mismo nombre, Pedro de Navarra. Es necesario leer detenidamente y con sumo cuidado toda la documentación del pleito pues las rotundas afirmaciones, unas verdaderas y otras falsas, de cada una de las partes enfrentadas -mariscales y parroquianos- fueron utilizadas según su conveniencia, ya que datos reales se mezclaban con argumentos completamente fantaseados. En estas circunstancias es fácil incurrir en errores.

La mayor parte de la historiografía cree que el sepulcro ya fue utilizado por los mariscales desde 1450, teoría que también compartimos. Es muy probable que el enterramiento comenzara a ser utilizado inmediatamente, tras el fallecimiento del Mariscal, en Estella, el año 1450. Desde luego, ya

\footnotetext{
14 "Pleito de la Parroquia de San Pedro de la Rúa..., Escrito sobre la jactancia de que la Capilla Maior de S. Pedro es de los Marqueses", Archivo Parroquial de San Pedro de la Rúa de Estella, Caja 020, 1579, Fajo 4º, 27, fol. 1v.

15 "Pleito en Archivo Duques de Villahermosa", Estado Cortes, leg. 9, I (830 folios), tomado de J. GOÑI GAZTAMBIDE, Historia Eclesiástica de Estella..., pp. 115116.
}

estaba en uso en 1457, momento en el que, incluso, la capilla mayor era llamada "del mariscal Felipe de Navarra"16. Un dato interesante a favor de este argumento es el hecho de que el Mariscal Pedro de Navarra y Alonso de Peralta, Conde de Santesteban, estuvieron presentes como representantes del rey, durante el juramento que Juan III y Catalina de Foix hicieron en 1496, confirmando los fueros de Estella ${ }^{17}$. Por ello, consideramos que, al ser la iglesia de San Pedro de la Rúa su panteón familiar, está perfectamente justificada su presencia en un acto de suma importancia, como era la confirmación de los Fueros por los Reyes de Navarra. Además, la inequívoca estructura gótica del arcosolio nos hace creer que el sepulcro fue acondicionado a mediados del siglo XV y no, como se pretende, en el siglo XVI.

\section{La cripta de los Mariscales de Navarra o la conquista del espacio sagrado por los po- derosos}

Con el paso del tiempo, es muy probable que el sepulcro en el arcosolio del presbiterio de San Pedro adquiriera gran protagonismo, quedándose pequeño para seguir recibiendo los restos de los sucesivos Mariscales de Navarra. Sin duda, esta fue una de las razones, junto al deseo de magnificencia y demostración de poder y riqueza, por la que se decidió construir una cripta en el centro del presbiterio. En 1552, pocos años después del cambio del sagrario al altar mayor, Pedro de Navarra (1522-1556), octavo Mariscal y primer Marqués de Cortes gracias a la compra del título por 24.000 ducados, traslada la sepultura de los Mariscales

\footnotetext{
16 J. GOÑI GAZTAMBIDE, Historia de los obispos de Pamplona II. Siglos XIV y XV, Pamplona, 1980, p. 506.

17 El juramento de los Fueros de Estella es prestado por los reyes Catalina de Foix y Juan III los días 9 y 17 de marzo de 1496, respectivamente (M. OSÉS URRICELQUI, Documentación medieval de Estella (siglos XII-XVI), "Corpus Documental para la historia del Reino de Navarra", Serie II, Pamplona, 2005, doc. 269, pp. 746-747).
} 
de Navarra a los pies del altar, en el centro de la capilla mayor ${ }^{18}$; así lo reconocen constantemente los parroquianos años más tarde “...porque los balaustres y Rejado y túmulo que ahora están lo hizieron y levantaron año de $1552^{\prime \prime 19}$.

Pedro de Navarra falleció en Toledo en 1556 y fue, provisionalmente, enterrado en San Juan de los Reyes; al año siguiente, el 23 de mayo de 1557, recibe sepultura "debaxo y junto al altar mayor de la dicha yglesia" de San Pedro de la Rúa donde se le había fabricado una sepultura nueva junto a sus antepasados ${ }^{20}$. El nuevo emplazamiento contemplaba la construcción de un espacio abovedado bajo tierra, para los restos de los mariscales, y un túmulo, es decir, una parte elevada -y no a ras del suelo como lo ordenaba la legislación de la época-, que provocó las consiguientes quejas de la feligresía: “... ni tampoco deben tener el túmulo levantado que tiene porque los balaustres y rejado y túmulo que ahora están lo hizieron y levantaron año de 1552 no lo pudiendo ni debiendo hazer por ser contra prematica y ley deste reyno y contra lo que el concilio tridentino manda" ${ }^{21}$. Además, "el túmulo de los mar-

\footnotetext{
${ }^{18}$ Archivo Duques de Villahermosa, Estado Cortes, leg. 7, G, 12 y 13, tomado de J. GOÑI GAZTAMBIDE, Historia Eclesiástica de Estella..., p. 110; J. AIZPÚN BOBADILLA, “Ubicación de los enterramientos y el sagrario...", p. 107.

19 “Escripto sobre la Jatancia de que la capilla es de los marqueses", Archivo Parroquial de San Pedro de la Rúa, Caja 20, 1579-1751, Fajo 4ํㅜ, no 27.

20 “Pleito de la Parroquia de San Pedro de la Rúa..., Auto que quando se enterro el Marques D. Pedro de Navarra que murió en Toledo y depossitado en S. Juan de los Reyes combento de franciscos año de 1557", Archivo Parroquial de San Pedro de la Rúa de Estella, Caja

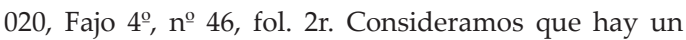
error en la documentación sobre el orden de sucesión de los mariscales, pues este Pedro de Navarra $(+1556)$ sería el octavo Mariscal y no el sexto, como dice el encabezamiento del documento.

21 “Pleito de la Parroquia de San Pedro de la Rúa..., Escrito sobre la jactancia de que la Capilla Maior de S. Pedro es de los Marqueses", Archivo Parroquial de San Pedro de la Rúa de Estella, Caja 020, Fajo 4º, 27, fol. 2r.
}

queses está tan pegado al altar mayor, que estorba para las misas cantadas y para las exequias reales, y no deja sitio para enterrar en depósito, si muere en la ciudad algún rey, príncipe o prelado..." ${ }^{22}$.

Afortunadamente, la documentación es bastante explícita sobre las características constructivas de la cripta. El 3 de octubre de 1655 el vicario general Jerónimo de Rada, a petición de la parroquia, acudió a la iglesia de San Pedro y "...visitó el sepulcro del centro, bajó al mismo y lo hizo medir... ya que el marqués sostenía que su bóveda ocupaba toda la capilla mayor y que por tanto ésta era suya, cosa que negaban los mayordomos y diputados... Abrieron las paredes de la bóveda del sepulcro por dentro, sacaron piedras y se comprobó que la bovedilla no ocupaba toda la capilla mayor, sino que tenía dos varas y tres cuartas, al paso que la capilla mayor medía diez varas y tenía tercia de anchura..." 23 .

La construcción de la cripta se vio favorecida por el claro desnivel que el terreno presentaba desde la cabecera hacia los pies (Fig. 4); si observamos las basas de las columnas que articulan el ábside central parece que el suelo del presbiterio ya era muy alto en el románico. Esto podía hacer pensar en la posible existencia de una cripta anterior, sin embargo, las excavaciones llevadas a cabo recientemente han confirmado lo contrario. Desde el punto de vista arqueológico, las catas han demostrado que para realizar la cripta en medio del presbiterio hubo que socavar el área central, ya en niveles geológicos, para disponer la cámara sepulcral. Por esta razón, la cimentación quedó visible en ambos tramos rectos, para lo que se hubo de anteponer dos muros de forro que, posteriormente, decoraron con pintura. Para su

\footnotetext{
22 "Pleito en el Archivo Duques de Villahermosa", Estado Cortes, leg. 9, I (830 folios), tomado de J. GOÑI GAZTAMBIDE, Historia Eclesiástica de Estella..., pp. 115116.

23 J. GOÑI GAZTAMBIDE, Historia Eclesiástica de Estella..., pp. 130-131.
} 
construcción practicaron un gran corte que alcanza y horada el nivel natural, abriendo el espacio necesario para la cripta $\left(3^{\prime} 38 \mathrm{~m}\right.$. de $\mathrm{E}$ a O; 2'58 de $\mathrm{N}$ a S). Ésta iría cubierta por una gran lauda de piedra, descubierta en las excavaciones, con decoración en relieve en la que se puede apreciar el escudo de Navarra con un león rampante, que aún conserva dos de las cuatro argollas de hierro que tuvo en origen (Fig. 5). Los muros del ámbito funerario son de sillería de distinto tamaño, unidos con mortero, y configuran un espacio rectangular con dimensiones internas de 2,16 m de longitud E-O y de 1'95 m de anchura en el eje N-S, con un grosor de muros entre $30 \mathrm{y}$ $33 \mathrm{~cm}$. (Fig. 6). La cripta se cubre con bóveda rebajada, cuya altura, desde la clave, es de $1^{\prime} 50 \mathrm{~m}$. El suelo se realizó con grandes lajas sobre las que se sientan los muros, de lo que se deduce que el pavimento se dispuso antes que el cerramiento e, incluso que ya existía, aunque se puede afirmar con rotundidad la existencia de una cripta anterior ${ }^{24}$ (Fig. 7). En su interior se han hallado restos de distintas inhumaciones y algunos objetos que proceden de ajuares funerarios como, por ejemplo, una espada de ceñir incompleta ${ }^{25}$ (Fig. 8) y un crucificado de terracota, al que le faltan los brazos y la pierna derecha, con restos de policromía en rojo, azul y marrón, y un orificio en el centro del pecho para la sujeción al soporte ${ }^{26}$ (Fig. 9).

${ }^{24}$ J. GARCÍA GAZÓLAZ, M.A. MARTÍN CARBAJO et alii, "La iglesia de San Pedro de la Rúa de Estella (Navarra)...", pp. 185-186.

${ }^{25}$ Se conserva parte de la guarnición (concha, empuñadura, guardamano y pomo decorado con retratos), parte de la hoja y la punta, recubierta por la vaina. Según la tipología de Norman (A.V.B. NORMAN, The Rapier and the small-sword, 1460-1820, Londres-Nueva York, 1980, pp. 199-212), esta espada respondería a las realizadas a partir de 1640 y sería del tipo 112; la mayor parte de los ejemplos conocidos son del siglo XVIII, como parece ser este ejemplar a juzgar por su decoración y los bustos que la decoran; J. GARCÍA GAZÓLAZ, M.A. MARTÍN CARBAJO et alii, "La iglesia de San Pedro de la Rúa de Estella (Navarra)...", pp. 226-230

26 Por la composición anatómica del crucificado, el canon estilizado y la cadera visible, se puede fechar en torno a finales del siglo XVI, quizás de procedencia

\section{EL LARGO PLEITO POR LA POSESIÓN DE LA CAPILLA MAYOR Y LA OBSESIÓN POR EL ESPACIO PRIVILEGIADO}

La presencia de escudos con las armas de los Mariscales y Marqueses de Cor$\operatorname{tes}^{27}$, ya fuera en el arcosolio, en la cripta e, incluso, en los soportes y arcos de la capilla mayor, hizo pensar a unos y a otros que la propiedad de la capilla mayor pertenecía a esta noble familia. Esta circunstancia fue la que provocó el comienzo de un larguísimo y complejo pleito, entre 1579 y 1685, que enfrentó a los parroquianos y a los marqueses y que, a su vez, originó la riquísima documentación que estamos utilizando para este trabajo $^{28}$.

francesa (J. GARCÍA GAZÓLAZ, M.A. MARTÍN CARBAJO et alii, "La iglesia de San Pedro de la Rúa de Estella (Navarra)...", pp. 225-226).

27 De hecho, en más de una ocasión las armas de los Mariscales fueron confundidas con las armas reales, pues aquellas incorporan en un cuartel el emblema de los reyes de Navarra: “... Yten que en el enterramiento que ahora los marqueses tienen en mitad de la capilla estaba antes dellos enterrada en el mismo lugar un ynfante o infanta y esto por tradiçion es muy publico y notorio y allende desto se colige y entiende ser esto ansi por el túmulo dorado que estaba en mitad de la capilla sobre la sepultura de la infanta o ynfante el qual tiene las armas reales que son una banda dorada en colorado y unas flor de lises con las bandas y armas reales de Aragón y tomando los marqueses la misma sepultura de los infantes también tomaron y se sirvieron del otro túmulo real..." ("Pleito de la Parroquia de San Pedro de la Rúa..., Articulado antiguo de la parroquia contra el marques de Cortes, noviembre de 1579", Archivo Parroquial de San Pedro de la Rúa de Estella, Caja 020, Fajo $4^{\circ}, 5$, fol. 5). En 1579, los vecinos atribuyen la realización del templo a tiempos del rey Sancho Ramírez, argumentando su emplazamiento a los pies del castillo real, las dimensiones de la fábrica y la presencia de un escudo con las armas reales (cadenas en campo rojo) pincelado en el arco del evangelio dentro de la capilla mayor y en el arco paralelo de la epístola (éstas borrosas). Creían ver "en medio de la capilla mayor... una media sepultura real, en la que se veían las armas de Navarra y Aragón y la flor de lis, y en muchas partes dos letras juntas gruesas C y A góticas", iniciales del personaje allí enterrado (Archivo Duques de Villahermosa, leg. 9, I, fols. 54-96, tomado de J. GOÑI GAZTAMBIDE, “La parroquia de San Pedro de la Rúa...", p. 174).

28 “Pleito de la Parroquia de San Pedro de la Rúa..., 
Juan de Benavides, noveno Mariscal (1556-1563), y Jerónima de Navarra, Marquesa de Cortes, también reposan en la misma capilla ${ }^{29}$. La situación de máxima tensión entre los procuradores de la parroquia y la familia de los Mariscales estalló con motivo del traslado a Estella de los restos de Ana de Navarra y Benavides, única hija del último Mariscal. Ésta había aumentado la dotación de capellanías y, tras su fallecimiento acaecido en Madrid el 8 de febrero de 1579, había dispuesto ser enterrada en San Pedro de la Rúa. Los parroquianos se oponían a que le diesen sepultura en su iglesia, alarmados ante el aumento de las pretensiones y de las intromisiones de los Navarra, pues iban multiplicando los escudos y los actos de posesión, se habían hecho con el patronato de la capilla mayor y ahora comenzaban a decir que era suya ${ }^{30}$.

Así ocurre con el articulado que presenta Pedro Fernández de Velasco, gobernador del Estado de Cortes, el 19 de marzo de 1580 en el que, de nuevo, vindicaba la propiedad de la capilla mayor de San Pedro para sus amos, los Marqueses. La argumentación se basaba en que el enterramiento era un túmulo de bóveda que ocupaba todo el ancho de la capilla, con rejas alrededor y el escudo de armas de los Mariscales y los Marqueses de Cortes: "la capilla mayor... con los dos arcos de los lados della, de tiempo inmemorial ha sido y es de los mariscales y marqueses de Cortes". Las armas de los Mariscales

Imbentario de todos los instrumentos que se an allado en el Archivo de la Yglesia maior de San Pedro, pertenecientes a los Pleitos que la dicha Yglesia a tenido y llevado contra los Señores Marqueses de Cortes; por muchos años, desde el de 1579 al delante hecho por D. Miguel de Yrujo y Ezpeleta, Beneficiado de dicha Yglesia, año de 1712", Archivo Parroquial de San Pedro de la Rúa de Estella, Caja 020, 1579-1751, Índice, Fajo 4o; "Pleito en el Archivo Duques de Villahermosa", Estado Cortes, leg. 9, I tomado de J. GOÑI GAZTAMBIDE, Historia Eclesiástica de Estella..., pp. 115-116.

29 J. GOÑI GAZTAMBIDE, Historia Eclesiástica de Estella..., p. 110.

${ }^{30}$ Id., "La parroquia de San Pedro de la Rúa...", p. 170; Id., Historia Eclesiástica de Estella..., p. 110. aparecían encima y a los lados de los arcos, en la caja del relicario del Santísimo Sacramento y en los pilares de piedra que están a los lados de la reja de la capilla; Asimismo, se exhibían en las rejas y en otras partes del presbiterio ${ }^{31}$.

Cinco días después, la parroquia presentaba en el Consejo Real de Navarra sus puntos de vista, como es lógico, diametralmente opuestos a los del gobernador. Para los parroquianos, que intentaban demostrar su primacía en la posesión de la capilla mayor frente a los Navarra y Peralta, Leonel y Felipe de Navarra no estaban enterrados en Estella pues, según ellos y como ya hemos comentado, el primer Mariscal sepultado en la capilla mayor de la parroquia fue don Pedro de Navarra, séptimo Mariscal en el orden de sucesión, que murió en Simancas, ya que sus antepasados se habían enterrado todos en La Oliva. Después de oír las declaraciones de muchos testigos el Consejo Real de Navarra dictó un veredicto que no satisfizo a ninguna de las dos partes con lo que éstas siguieron litigando. El 24 de septiembre de 1581, el Marqués de Almazán, virrey de Navarra, emitió una nueva sentencia arbitral: por un lado, la capilla mayor era propiedad de la iglesia parroquial y de sus parroquianos para todos los usos parroquiales, como hasta ese momento; por otro, el enterramiento en dicha capilla, tal y como estaba, era propio de los Marqueses de Cortes, los cuales podían tener en ella capellán mayor y capellanes que celebrasen misas cantadas y rezadas y tocaran las campanas, como hasta el citado momento. Además, podían continuar exhibiendo las armas en la capilla y en los pilares, como se había realizado hasta entonces ${ }^{32}$.

\footnotetext{
${ }^{31}$ Archivo Duques de Villahermosa, Estado Cortes, leg. 7, G. n. 32, tomado de J. GOÑI GAZTAMBIDE, Historia Eclesiástica de Estella..., p. 119.

${ }^{32}$ Archivo Duques de Villahermosa, Estado Cortes, leg. 9, I, fols. 779-78; leg. 7, n. 18 y 19, tomado de J. GOÑI GAZTAMBIDE, Historia Eclesiástica de Estella..., pp. 119121.
} 
Los argumentos de una y otra parte sobre la posesión de la capilla mayor son muy numerosos a lo largo de estos años, en los que la cripta abovedada y su utilización por parte de la familia se convierten en el elemento diferenciador. En favor de los marqueses se arguye: “... Iten que el entierro de dicha parte tiene dentro de la dicha su Capilla mayor no es sepultura como Las partes contrarias alegan sino entierro con grande edificio muy antiguo y con una bobeda debajo de tierra demucha capacidad y ostentación para enterrar como se enterraron y entierran en el el infante D Leonel de Navarra y sus descendientes marichales y marqueses en cortes y para sus criados tiene y a tenido mi parte y sus ascendientes dos sepulturas en La primera ilera después del Januado ${ }^{33}$ de la dicha Capilla mayor como Lo diran Los testigos..." ${ }^{34}$. Por el contrario, los parroquianos entienden que "no cabe que la capilla de Ella -de la iglesia de San Pedro- sea de nadie sino parroquial como lo es y no suya de los dichos marqueses como lo dizen publican y pretenden... y ansi no es suya ni la pueden llamar suya ni tampoco debe tener el túmulo levantado que tiene..." ${ }^{35}$.

El tiempo pasa y la situación entre las partes litigantes es cada vez más tensa, aunque se siguen permitiendo ciertos

\footnotetext{
33 Jaunado: Presbiterio, siglos XVII y XVIII (Pamplona). Sitio de la iglesia donde se sientan los señores. Del vasco jaun, señor. Jaunado: Presbiterio de la iglesia en donde eran sepultados los "jaunak" o señores del lugar en urnas de piedra o mármol (Montaña) (J.M. IRIBARREN, Vocabulario navarro, Pamplona, 1997, $3^{\text {a }}$ ed., p. 284).

34 “Cédula en derecho de los parrochianos de San Pedro y otros papeles del Marques sobre la capilla contra el marques de Cortes y su articulado", Archivo Parroquial de San Pedro de la Rúa, Caja 20, 1579-1751, Fajo $4^{\circ}$, nº 2; "Articulado añadido de los Marqueses de Cortes sobre decir es suya la Capilla Maior de San Pedro", redactado por Sancho de Esturiza, procurador de la Marquesa de Cortes, Archivo Parroquial de San Pedro de la Rúa, Caja 20, 1579-1751, Fajo 4º, ํํ 2.

35 “Escripto sobre la Jatancia de que la capilla es de los marqueses", Archivo Parroquial de San Pedro de la Rúa, Caja 20, 1579-1751, Fajo 4ºำ nº 27.
}

privilegios para el túmulo de los mariscales, que se mantiene sobreelevado respecto a las demás sepulturas, que debían estar llanas. Así, en 1616, el obispo Fr. Prudencio de Sandoval exige que "los que tienen sepulturas, las allanen a nivel, de manera que el suelo de la iglesia esté llano, excepto el túmulo de la capilla mayor" ${ }^{\prime \prime 3}$.

No obstante, los problemas continúan y, el 3 de octubre de 1655, el vicario general, Jerónimo de Rada, a petición de la parroquia, realizó una nueva visita a la iglesia de San Pedro. Los documentos recogen que en la zona del Evangelio vio el sepulcro de los marqueses con sus armas y, además, bajó al sepulcro del centro; en un rincón, fuera de su sitio, halló la reja que cerraba la capilla mayor. Al día siguiente, de nuevo examinó el edificio, junto con oficiales nombrados por ambas partes, para reconocer el sepulcro central, comprobando que sus dimensiones eran más reducidas que la extensión del presbiterio, como ya se expresó anteriormente. Años después, tras la apelación de los mayordomos al Tribunal de la Rota, éste pronunció dos sentencias manteniendo al Marqués de Cortes en posesión de la capilla, aunque no en la propiedad, y declarándolo patrono de la misma en cuanto al uso del sepulcro, nombramiento de capellanes, uso de los ornamentos, adorno de la capilla con tapices bordados con su escudo de armas, etc...

Tras estas inspecciones, la cripta fue de nuevo sellada, quizás en el siglo XVIII. Para ello, se cubrió y tapó con un relleno de tierra elevando así el nivel del suelo y

\footnotetext{
${ }^{36}$ El 3 de enero de 1616, el licenciado Juan de Valle, chantre, provisor y vicario general de Pamplona, visitó la iglesia y revisó meticulosamente las cuentas en presencia del obispo fray Prudencio de Sandoval; después, el obispo, dejó 22 mandatos de visita, entre los que destaca el que acabamos de señalar aunque cuatro años más tarde nadie había tocado las sepulturas. Se amenazaba con que si en el plazo de tres meses no eran allanadas, la iglesia se haría dueña de ellas y las vendería (14 de junio de 1620) (J. GOÑI GAZTAMBIDE, Historia Eclesiástica de Estella..., pp. 165-166).
} 
alcanzando, prácticamente, la cota que, antes de la excavación, tenía esta zona de la iglesia. Asimismo, se levantaron los antepechos de cierre con un probable acceso en la zona central por medio de una escalinata ${ }^{37}$. Este hecho puede estar relacionado con la decadencia de la familia de los mariscales entre la sociedad navarra.

\section{LAS REFORMAS DE LA IGLESIA EN ÉPO- CA MODERNA: VICISITUDES Y MISERIAS DE LA FÁBRICA}

Durante la Edad Moderna, la mayor parte de las intervenciones en la iglesia de San Pedro, fueron destinadas a la conservación de la fábrica medieval ${ }^{38}$ pues, ya a mediados del siglo XVI, el edificio presentaba un precario estado, según se recoge en la documentación. De la misma manera, las excavaciones arqueológicas han constatado que hubo necesidad de aplicar sistemas de refuerzo, a base de piedra y abundante mortero, alrededor de los pilares de la nave central, sobre todo, en los septentrionales ${ }^{39}$. Asimismo, los pilares cilíndricos que separan las naves también fueron reforzados para contrarrestar la debilidad estructural de la fábrica, con lo que han perdido su aspecto original $^{40}$.

\footnotetext{
${ }^{37}$ GARCÍA GAZÓLAZ, M.A. MARTÍN CARBAJO et alii, "La iglesia de San Pedro de la Rúa de Estella (Navarra)...", pp. 235-236.

38 Para todo lo referente a las fases constructivas medievales de San Pedro de la Rúa véase Ma C. MUÑOZ PÁRRAGA y Mํa T. LÓPEZ DE GUEREÑO SANZ, "Las fábricas medievales..."

${ }^{39}$ GARCÍA GAZÓLAZ, M.A. MARTÍN CARBAJO et alii, “La iglesia de San Pedro de la Rúa de Estella (Navarra)...", p. 233.

${ }^{40} \mathrm{M}^{\mathrm{a}}$ C. MUÑOZ PÁRRAGA y Mำ T. LÓPEZ DE GUEREÑO SANZ, “Las fábricas medievales...”, pp. 3842. Prueba de esta necesidad de refuerzo es el hecho de que la parroquia dio una sepultura de gracia a Isabel de Ganuza, mujer de Bernabé Imberto, porque la otra que tenía -entendemos que con anterioridad al refuerzo de los soportes-, la ocupaba el pilar del Evangelio (J. GOÑI GAZTAMBIDE, Historia Eclesiástica de Estella..., p. 235).
}

Estas reparaciones no fueron impedimento para continuar con la tradición iniciada por los reyes navarros pues, el 8 de octubre de 1523, Carlos V visitaba la iglesia $y$, tras subir a pie al templo bajo palio, rezó unos instantes en la capilla mayor ${ }^{41}$. Años más tarde, entre el 17 y el 18 de noviembre de 1592, Felipe II, durante su estancia en Estella, no pudo visitar la parroquia de San Pedro pero ésta vio compensada la ausencia del monarca con la promesa de una limosna para la reliquia de San Andrés, aunque tardó tres años en recibirla ${ }^{42}$.

Asimismo, la familia de los Mariscales de Navarra, en su afán por demostrar su condición de propietarios, no sólo de la capilla sino también de toda la iglesia, participó de forma recurrente en los sucesivos reparos acometidos en el templo. Cuando, en 1557, se celebraron las ceremonias del entierro de don Pedro de Navarra, oficiadas por su hermano, don Francisco de Navarra, Arzobispo de Valencia (1556-1563), éste pudo comprobar in situ el precario estado del templo: "... de algún jubileo, o indulgencia con que se pudiesse coger alguna Limosna para reedificar La Bobeda dela Yglesia que estaba dirruida, y los testigos de ella lo que mas dicen es que el Arzobispo de Valencia D. Francisco de Navarra Reconoziendo la Pobreza y imposibilidad dela Ylgesia dio de limosna alguna cantidad para cimbrarla y ofreció que la reedificaría, y que murió sin hazerla..." ${ }^{43}$.

41 Charles de Dicastillo, notario público y secretario del ayuntamiento de Estella, resalta el juramento del emperador de los Fueros, Privilegios y Libertades, Usos y Costumbres de la Ciudad; Ambrosio de Morales se fija en la devoción del monarca ante la reliquia de San Andrés (Antigüedades de España, lib. 9, cap. VII, p. 243) y Lezáun manifiesta que, cuando visitó la santa capilla, dejó a San Andrés una limosna de 200 ducados (B. de LEZÁUN Y ANDÍA, Memorias históricas de la ciudad de Estella, 1698, reed. Pamplona, 1990). Por su parte, Goñi Gaztambide describe con detalle la recepción que hizo la ciudad de Estella al emperador (Historia Eclesiástica de Estella..., pp. 100-103).

42 J. GOÑI GAZTAMBIDE, Historia Eclesiástica de Estella..., p. 103.

43 “Cédula en derecho de los parrochianos de San 
Tal era la situación que, tanto el prelado como el Marqués Juan de Benavides, trataron infructuosamente con la parroquia para que la iglesia de San Pedro se trasladase a donde estaba la casa de Lope de Ezpeleta, en la zona baja. Entre tanto, y para intentar detener la ruina del templo, el Arzobispo, propietario de dicha casa, empleó su madera para cimbrar y apuntalar la bóveda de la nave central por 600 ducados $^{44}$.

Por otra parte, ante la fragilidad estructural del templo Don Francisco hizo llamar, a su costa, al "maestro de la iglesia mayor de Burgos" para que emitiera un informe sobre el estado del edificio. De la misma manera fueron convocados los maestros Antón de Anoeta, de Miranda de Arga, Miguel de Amézqueta, Antón Peña y Miguel de Aserrea, vecinos de Estella, el maestro Lázaro -que se encontraba trabajando entonces en la iglesia de Santiago de Puente la Reina- y el maestro guipuzcoano Juan de Villarreal, que fue maestro mayor y veedor del obispado de Pamplona. El dictamen emitido por dichos maestros, seguramente muy condicionado por los intereses de los Navarra, fue unánime, es decir, el deterioro era tan profundo que era preciso derribar la iglesia y reconstruirla. Esta injerencia de los Mariscales provocó una airada disputa por parte de la parroquia quien, en 1568, comienza a recabar datos que prueben la antigüedad de la iglesia de San Pedro de la Rúa, la principal de Estella, y por lo que sabían "desde hace muchos años está muy vieja y amenaza ruina. Las paredes, capillas y hornuras están tan molidas y gastadas, que no tienen remedio. Las bóvedas y las capillas, desde

Pedro y otros papeles del Marques sobre la capilla contra el marques de Cortes y su articulado", Archivo Parroquial de San Pedro de la Rúa, Caja 20, 1579-1751, Fajo $4^{\circ}, \mathrm{n}^{\circ} 2$.

44 Archivo Duques de Villahermosa, Estado Cortes, leg. 7, G 23, Memorial Anónimo, tomado de J. GOÑI GAZTAMBIDE, "La parroquia de San Pedro de la Rúa...", p. 170; Id., Historia Eclesiástica de Estella..., p. 111. hace unos diez o doce años, están medio abiertas, de suerte que parece que con dificultad se tiene una piedra a otra" ${ }^{45}$.

Todas estas actuaciones parecían justificadas pues la peligrosidad de la fábrica era tan importante que, incluso, los parroquianos estaban dejando de asistir a los oficios por miedo a que se cayese la bóveda. Así, a finales de 1567, en las Cortes celebradas en Estella, en noviembre-diciembre, se ordenó una procesión general, pero el virrey abandonó la iglesia de San Pedro por temor al hundimiento de la bóveda; incluso, el abad del cercano monasterio de Irache, en uno de sus sermones, dijo que acudir a la iglesia de San Pedro era tentar a Dios. Por ello, se tomó la decisión de encolar la bóveda para evitar daños mayores. En 1568 la iglesia ya se encontraba toda cimbrada, con los arcos y bóvedas apuntaladas, pues habían fallado los cimientos que, tal y como han demostrado las excavaciones, no eran excesivamente sólidos ${ }^{46}$.

En 1572, el estado de la bóveda de la nave central empeoró a consecuencia de las piedras que cayeron sobre ella por el derribo del castillo de Zalatambor, construido sobre la peña ${ }^{47}$. A raíz de los daños ocasio-

45 J. GOÑI GAZTAMBIDE, “La parroquia de San Pedro de la Rúa...", pp. 170-171; Id., Historia Eclesiástica de Estella..., pp. 111-112.

46 J. GOÑI GAZTAMBIDE, “La parroquia de San Pedro de la Rúa...", p. 171; Id., Historia Eclesiástica de Estella..., p. 112.

47 En el pleito con el gobernador del Estado de Cortes, los mayordomos y parroquianos de San Pedro declaran "...que la dicha iglesia ha mucho tiempo que ha estado y está muy necesitada de reparo por estar, como están, las paredes en muchas partes abiertas y gastadas por su antigüedad, y estar derruido del todo la metad del claustro y mas particularmente una capilla de la invocación de Sant Salve, que está del todo caída, y otra capilla de la invocación de la Trinidad, que está también derruida un gran pedazo della, y así la dicha iglesia está muy necesitada de reparo así lo principal della como en el claustro y capillas particulares. Otrosí, que al tiempo que se desmanteló la dicha fortaleza, por estar encima de la dicha iglesia, derribaron la mitad del claustro della las piedras que de lo alto caían rodando 
nados por el derrumbe, los mayordomos de la iglesia intentaron realizar algunos reparos y consultaron, una vez más, con otros peritos quienes, en esta ocasión y examinado de nuevo el edificio, concluyeron que no había peligro en quitar los puntales y cimbras y que se podía sujetar la bóveda con unas facas de madera de haya. Esta medida fue aceptada por la parroquia quien, en 1576, acometió las obras a su cargo ${ }^{48}$. Debe ser en este momento cuando se colocan los tirantes de arcos rebajados que unían los soportes de la nave central y de los que sólo subsiste el llamado "arco del miedo", entre los soportes próximos al presbiterio, pues el del coro fue eliminado aunque aún se aprecian los arranques (Fig. 10). También debe ser ahora cuando se refuerza con un arco de medio punto el formero del tramo central, entre la nave central y la de la Epístola, aunque aún se pueden apreciar los baquetones originales del arco apuntado, y la embocadura del ábside meridional.

Durante los primeros años del siglo XVII se suceden constantes visitas de peritos que, llamados por unos o por otros, informan sobre el estado de peligrosidad de la iglesia. Así, en 1600, llega un oficial procedente de San Martín de Unx. Meses más tarde se sospecha que la bóveda de la nave mayor amenazaba ruina y son llamados

de la dicha fortaleza, las cuales daban en los pilares del claustro, y el dicho derrueco de la fortaleza causó el derrueco del claustro de la dicha iglesia". Martín de Riezu, escribano real vecino de Estella, declara que al tiempo del derribo las piedras caían de lo alto del castillo con mucho ímpetu contra los pilares y arcos del claustro, "y de los grandes y recios golpes que daban, derribaron mucha parte de los dichos pilares y arcos que estaban hechos de muchos años a esta parte, que según estaban labrados con muchas figuras y labores hechas... y así la mitad del dicho claustro, arcos, pilares y capilla de la invocación del Señor San Salve quedaron derribados y también parte de la capilla de la invocación de la Trinidad quedó muy derruida" (J. GOÑI GAZTAMBIDE, "La parroquia de San Pedro de la Rúa...", p. 171; Id., Historia Eclesiástica de Estella..., p. 113).

48 J. GOÑI GAZTAMBIDE, “La parroquia de San Pedro de la Rúa...", p. 172; Id., Historia Eclesiástica de Estella..., p. 114. nuevos expertos. El 5 de mayo de 1601 los canteros Juan de Aguirre, vecino de la villa de Larraga, Domingo de Olariaga, vecino de Idiazábal y Julián Fernández, vecino del lugar de Baquedano declaran el mal estado de los muros de la iglesia y proponen rebajarlos hasta la altura de la cabecera: “...an visto y rreconozido la nave y partes necesarias que a abido de ver y rreconozer del sentimiento que seaecho en la dicha nave y yglesia y del daño que se alla y delo quees necesario para su rreparo y conserbación y bisto y rreconocido ocularmente dixeron que para abaxar las capillas altas y el tejado y paredes dela dicha iglesia como conbiene y en buena proporcion mirando toda la iglesia por dentro y fuera y encima las capillas della y la torre con todo lo demás que berse debía y que allan que las paredes dela dicha iglesia están sentidas y rrequebraçadas por las grandes antiguas [tachado] paredes antiguas y cargadas que en ellas hay y les pareze a todos tres unánimes y conformes que se baxen las paredes dela dicha iglesia con sus tres capillas hasta en par de la cavecera de la dicha iglesia de manera que queden las dichas capillas bien proporcionadas y buenas y para esto an tasado la costa que puede tener las capillas y tejado y las dos paredes y el caracol questa enizia el calostro y la costa que an de tener de bajarse todo esto y los andamios y el hazerlos con la compra dela madera y cimbrias y hacerlos para deshazer y baxarlas con toda la costa que en lo suso dicho se ofrece les a parecido y les parece que terna de costa quinientos ducados ansi en hazer los dichos andamios y baxar el tejado y las tres capillas y paredes y caracol como esta dicho. Ecepto un pedazo cerca de la torre que esta apegado a ella, que llega a una bentana grande el qual dizen que se quede sin deshacer a tento esta apegado ala dicha torre y se quede para refuerzo della. Y lo demás sedes barate hasta el fundamento de la dicha bentana questa encima dela puerta que esta en el cuerpo de la dicha yglesia, y que lo dicho les a parecido y pareze so cargo de sus conciencias..." ${ }^{49}$. En

49 “Obras del tejado de la iglesia 1601-1611, Declaración de tres oficiales canteros del riesgo en que está la 
1605 fueron los canteros Juanes de Yerategui y Martín de Ceanote los encargados de dar su opinión sobre la iglesia ${ }^{50}$.

El 29 de enero de 1606 se reunieron en la capilla de la Trinidad de San Pedro de la Rúa los diputados y mayordomos de la misma para otorgar poder sobre el daño de la iglesia, en el que se alude al reconocimiento que hicieron, en 1601, los citados Juan de Aguirre, vecino de la villa de Larraga, Domingo de Olariaga, vecino de Idiazábal y Julián Fernández, vecino del lugar de Baquedano quienes “...vieron y reconocieron las naves y partes necesarias que havido que ver y reconocer del sentimiento que a echo en la dicha nave e higlesia y del daño que se alla y de como es necesario que con brevedad se ponga el remedio e hicieren relacion que la nave de la dicha higlesia esta muy sentida y requebraçada por las grandes paredes y antiguas y cargadas que en ellas hay y que para el reparo y seguro de la dicha higlesia terna de costa mas de quinientos ducados...". Teniendo en cuenta esta circunstancia los citados canteros "... hacen relación porque se pretende hacer las capillas de la nave de la dicha higlesia todas ellas de ladrillo para que estén mas aliviadas las paredes de la dicha Iglesia con que quedara segura la dicha iglesia...", quedando también patente el problema de la financiación de las obras ${ }^{51}$.

A pesar de la claridad de estos informes y como si se tratara de una iglesia diferente, tras una serie de visitas de reconocimiento, el 9 de febrero de ese mismo año, el licenciado Bartolomé Vélez de

Iglesia y que necesita de rebajarse", Archivo Parroquial de San Pedro de la Rúa, Caja 47 bis, véase Apéndice documental 1.

${ }^{50}$ Archivo Parroquial de San Pedro, Libro II de Fábrica, fol. 14v; J. GOÑI GAZTAMBIDE, Historia Eclesiástica de Estella..., p. 233.

51 “Obras del tejado de la iglesia 1601-1611, Poder otorgado por los mayordomos y diputados de la higlesia mayor de la ciudad de sobre el daño de la iglesia", Archivo Parroquial de San Pedro de la Rúa, Caja 47 bis, Véase Apéndice documental 2.
Villanueva manifestó que no era necesaria reparación alguna pues "como se ha visto ocularmente, las dichas capillas están seguras para mucho tiempo y no tienen necesidad de reparo ninguno" ${ }^{\prime 2}$. Para él, era suficiente reparar los tejados con algunas maderas grandes para, así, descargar en las paredes algo del peso que gravitaba sobre las capillas. Como los muros presentaban aberturas, se rajaron y revocaron con buena piedra y cal. De hecho, según el visitador, se podían colocar fácilmente a nivel las dos o tres dovelas desniveladas de la bóveda de la capilla del coro, apoyando la bóveda con dos maderas en la clave y haciendo un andamio a poca costa. Era suficiente con que los mayordomos tuvieran "cal sobrada que sea muy buena y mezclada con poca arena hecha mortero de ocho o diez meses antes que se haya de gastar para rexar las aberturas que hubiere en las paredes y estribos donde sea necesario" ${ }^{\prime 53}$.

Por esos mismos años un Memorial Anónimo nos aporta seguramente una visión de la iglesia más cercana a la realidad y completamente diferente pues, según dice, se encontraba "molida en los primeros tercios de todos los arcos mayores y menores, do está a fuerza de toda la obra". Al parecer, las paredes estaban desplomadas y abiertas por diversas partes desde los cimientos hasta lo último de ellas y las bóvedas también estaban muy dañadas aunque "la capilla mayor e una de las colaterales están buenas" y se propone como solución "hacer paredones desde los cimientos y reforzar el pilar, cimbrar todas las capillas y bóvedas, como si se hicieran de nuevo, y todos los arcos de toda la iglesia; los pilares se han de apoyar por encima de los arcos con sus puntales buenos y que lleguen de pilar a pilar de trecho en trecho... Los arcos de la torre muestran

52 J. GOÑI GAZTAMBIDE, Historia Eclesiástica de Estella..., p. 234.

53 Libro I, Cuentas, fols. 413v y 420; Libro II, Cuentas 14, Archivo Parroquial de San Pedro; J. GOÑI GAZTAMBIDE, "La parroquia de San Pedro de la Rúa..."; Id., Historia Eclesiástica de Estella..., p. 234. 
algún poco sentimiento y bien poco..." ${ }^{54}$; incluso, se plantea deshacer la bóveda y rehacerla de ladrillo ${ }^{55}$.

Finalmente, el 29 de junio de 1609 se toma la decisión de desmontar la bóveda gótica de los tres tramos de la nave central para reconstruirla a menor altura. El 12 de julio de ese mismo año se sacó a postura la obra que fue adjudicada a Francisco del Pontón, maestro de Galaceano por 380 ducados $^{56}$. A lo largo de 1610 se realizaron los trabajos de desmontaje de la bóveda, por lo que ya no se pudo celebrar la fiesta del Corpus "por estar descubierta la iglesia" ${ }^{57}$. El capitán Pedro de Allo envió desde Sevilla la cantidad de mil reales para ayudar a cubrir la iglesia, por haberse rebajado mucho "por el notable peligro que tenía por su mucha altura y ser bóveda de piedra" ${ }^{58}$.

En 1611, se renovó el tejado, optando por la propuesta de Juan de Larrañaga, obrero de Estella, de hacerlo a cuatro vertientes aprobada, a su vez, por Juan de Urrutia, maestro de obras de Pamplona ${ }^{59}$. Al

${ }^{54}$ Archivo Duques de Villahermosa, Estado deCortes, leg. 7, G. 23, tomado de J. GOÑI GAZTAMBIDE, “La parroquia de San Pedro de la Rúa...", p. 177; Id., Historia Eclesiástica de Estella..., pp. 233-234.

55 J. GOÑI GAZTAMBIDE, “La parroquia de San Pedro de la Rúa...", p. 177.

${ }^{56}$ Para lo que hubo necesidad de desmontar el órgano (J. GOÑI GAZTAMBIDE, "La parroquia de San Pedro de la Rúa...", p. 177; Id., Historia Eclesiástica de Estella..., p. 234).

${ }^{57}$ Libro II de Cuentas, fol. 62v, Archivo de San Pedro de la Rúa; J. GOÑI GAZTAMBIDE, Historia Eclesiástica de Estella..., p. 234.

58 J. GOÑI GAZTAMBIDE, "La parroquia de San Pedro de la Rúa...”, pp. 177-178; Id., Historia Eclesiástica de Estella..., p. 234.

${ }^{59}$ Es abundante la documentación recogida en este sentido en el Archivo Parroquial de San Pedro de la Rúa (Caja 47 bis) sobre las maderas necesarias, las tejas y los ladrillos que habría que emplear para la reforma del tejado de la iglesia. Asimismo, se conservan la traza y condiciones para realizar la obra a cuatro vertientes a las que se compromete Juan de Larrañaga por un total de 340 ducados (Véase Apéndice documental 3) y la año siguiente, los sermones de la bula y de la Cuaresma se predicaron en San Miguel y San Juan por estar descubierta la iglesia de San Pedro ${ }^{60}$. En 1613 se terminó de pagar a Larrañaga "toda la obra que hizo cubriendo la iglesia" ${ }^{\prime \prime 1}$. El análisis de la documentación nos hace pensar que esta intervención se refiere al tejado y no a la bóveda de la nave central, pues aún en el siglo XVIII la iglesia aparecía en "texa vana".

Las intervenciones en la fábrica de la iglesia son constantes pues en 1678, Francisco de Retana, maestro cantero de Estella, hubo de reforzar por 330 ducados el pilar meridional de la capilla mayor, una de las zonas más problemáticas de la fábrica, al amenazar ruina $^{62}$. En 1731 la parroquia cree que la situación de la iglesia ha llegado a su límite pues su estado era de "mayor indecencia y fealdad a causa de hallarse el cielo de ella a texa vana y cruzarla dos puentes muy baxos, el uno del pilar del Evangelio hasta el pilar de la Epístola y el otro similar en el coro"63. Por lo tanto la renovada bóveda de la nave central no llegó a voltearse, tal y como se había propuesto en 1609, por lo que hubo necesidad de atirantar los soportes de la nave mayor ${ }^{64}$. Tras unas series de

aprobación dada por Francisco Palear Fratín al citado proyecto.

60 J. GOÑI GAZTAMBIDE, Historia Eclesiástica de Estella.., p. 235.

61 El mismo Juan de Larrañaga, en 1625, niveló el pavimento de la iglesia, poniendo a ras del suelo, todas las sepulturas. Ese mismo año se le concedió una sepultura de gracia por la realización de estas obras; la iglesia fue enlosada en 1632 (J. GOÑI GAZTAMBIDE, Historia Eclesiástica de Estella..., p. 235).

${ }^{62}$ Libro IV de Fábrica, fol. 24r. Goñi Gaztambide da la fecha de 1679 (J. GOÑI GAZTAMBIDE, “La parroquia de San Pedro de la Rúa...", p. 178).

63 J. GOÑI GAZTAMBIDE, "La parroquia de San Pedro de la Rúa...", p. 178; Id., Historia Eclesiástica de Estella..., p. 235. De éstos sólo conservamos el primero y aún se aprecian los arranques de los del segundo, que pudo ser desmontado en este momento.

${ }^{64}$ El deficiente estado de la bóveda gótica, con su consiguiente sustitución, debió ser provocado por un 
consultas a maestros como Mateo de Albéniz y Antonio Carramiola, ambos estelleses, los cercanos José Rayón, maestro de obras de gran prestigio, vecino de Calahorra, y Juan Larrea, de Berbinzana, y el facultado por el obispado Juan de Antonio de San Juan, se decide que el gasto de la obra no puede superar los 6.942 reales de vellón. Finalmente, en 1731, Domingo Oyaregui fue el encargado de acometer la reforma por 429 ducados, que consistió en quitar los dos puentes, cubrir la nave central, con una bóveda de cañón con lunetos de altura similar a la del ábside principal, y blanquear el interior (Fig. 10). Además, y aunque no estaba previsto, se cambió la escalera del coro ${ }^{65}$. Al quedar sobre el trasdós de la bóveda los primitivos ventanales góticos que iluminaban la nave central, la iglesia quedó muy oscura ${ }^{66}$.

El acentuado desnivel del terreno en el que se asentó la iglesia fue la causa de que las basas de los soportes de la cabecera y de los muros se sobreelevaran considerablemente. El nivel del presbiterio era muy alto respecto al de la nave, pues las basas del arco triunfal superan en más de un metro la altura del resto de los soportes del templo, lo que permitió que el espacio bajo las naves fuera utilizado para abrir sepulturas ${ }^{67}$. Así, el

fallo en la cimentación de las naves. Quizás, podamos relacionar con este estado provisional de la cubierta de la iglesia la línea de canecillos, en número de tres, que recorre cada lado de la nave central en su tramo oriental y que hoy quedan en el trasdós de la bóveda. Bien pueden corresponderse con alguno de estos tejados colocados antes de volteo definitivo de la bóveda. Algunos autores (C. MARTÍNEZ ÁLAVA, Del románico al gótico en la arquitectura de Navarra. Monasterios, iglesias y palacios, Pamplona, 2007, p. 281) creen erróneamente que la bóveda actual, rebajada respecto a su altura original hasta enrasar con la del ábside central, se construye en 1609.

${ }^{65}$ Libro IV de Fábrica, sin foliar, Archivo Parroquial de San Pedro de la Rúa; J. GOÑI GAZTAMBIDE, "La parroquia de San Pedro de la Rúa...", p. 178; Id., Historia Eclesiástica de Estella..., p. 236.

${ }^{66} \mathrm{M}^{\mathrm{a}}$ C. MUÑOZ PÁRRAGA y M $\mathrm{M}^{\mathrm{a}} \mathrm{T}$. LÓPEZ DE GUEREÑOSANZ, “Las fábricas medievales...”, pp. 38-42.

${ }^{67}$ De hecho, es probable que el nivel del pavimento de la iglesia románica fuera el que marca la puerta de la torre, espacio que quedaba entre el nivel geológico y el pavimento fue aprovechado en época moderna como lugar de enterramiento para los parroquianos de San Pedro de la Rúa ${ }^{68}$. La documentación recoge cómo este hecho ocasionó numerosas quejas por parte de las autoridades eclesiásticas que, constantemente, manifestaban su desagrado por el aspecto que presentaba el templo y el deseo de allanar todas las sepulturas pues, cabe suponer, que éstas obstaculizaban el paso, excepto la de los Mariscales de Navarra en el centro del presbiterio. Así, en 1592, se recogieron muchas limosnas de un real para allanar el suelo de la iglesia, obra que fue ejecutada por Juan Vizcaíno, vecino de Guirguillano, cantero, Martín de Berástegui y otros oficiales ${ }^{69}$.

en el muro Norte del primer tramo de la nave del Evangelio, similar al de los ábsides (Ma C. MUÑOZ PÁRRAGA y Mำ T. LÓPEZ DE GUEREÑO SANZ, “Las fábricas medievales...", pp. 31-36). Aunque no sabemos el momento preciso, seguramente con el paso del tiempo la cota de las naves fue descendiendo, lo que determinó la necesidad de hacer una escalinata para, de esa manera, salvar la desigualdad de niveles. Por otra parte, también podríamos argumentar la presencia de esa escalera cuando se lleva a cabo la realización de la cripta, lo que provocó una mayor altura del presbiterio. Dicha escalera debió ser sustituida pues, en 1900, el cantero Cayetano Echauri construyó una escalinata de piedra para acceder al presbiterio (J. GOÑI GAZTAMBIDE, Historia Eclesiástica de Estella..., p. 240).

${ }^{68}$ En las excavaciones arqueológicas se han encontrado hasta cinco niveles de enterramientos, con un total de 534 sepulturas en capas superpuestas. De ellos 390 son en conexión anatómica, el resto se corresponden con osarios. Es importante destacar que las fosas se localizan únicamente en el cuerpo de naves, sobre todo, en la nave central. La mayor densificación de tumbas la encontramos a los pies del templo, pues en esta zona los depósitos acumulados entre la base geológica y la cota de suelo son mayores que en la cabecera debido al desnivel del terreno. Como es sabido, los enterramientos en el interior de las iglesias se efectúan, de manera generalizada desde el siglo XVI y, sobre todo, hasta tiempos de Carlos III, quien prohibió dar sepultura a los fieles dentro de los templos y, por ello, ordenó crear cementerios alejados del entorno de las iglesias. Carlos IV y José Bonaparte tuvieron que legislar de nuevo sobre este aspecto (J. GARCÍA GAZÓLAZ, M.A. MARTÍN CARBAJO et alii, "La iglesia de San Pedro de la Rúa de Estella (Navarra)...", pp. 181-191).

${ }^{69}$ Archivo Diocesano de Pamplona, C/148, nำ10; J. GOÑI GAZTAMBIDE, Historia Eclesiástica de Estella..., p. 233. 
No obstante, los deseos y las disposiciones seguían incumpliéndose pues, en 1616, el obispo Fr. Prudencio de Sandoval exige que "los que tienen sepulturas, las allanen a nivel, de manera que el suelo de la iglesia esté llano, excepto el túmulo de la capilla mayor ${ }^{\prime \prime 7}$. El problema de las sepulturas seguía sin solucionarse pues, el 21 de septiembre de 1630, el licenciado Hualde y Hermosilla, visitador general por mandato del obispo Pedro Fernández Zorrilla ordena que "se quiten las piedras losas que están en la capilla de San Nicolás y que hasta que no se desembarace, no se diga misa en ella y se quiten las goteras de toda la iglesia" ${ }^{71}$. La situación persiste en 1745 ya que en ese año se acordó enlosar las sepulturas pues "el piso estaba muy indecente y no se podía andar por él sin grave peligro" ${ }^{\prime 72}$. Finalmente, en 1756, en la torre que, o no se había rematado o se había desmochado, se levantó un coronamiento de ladrillo para proteger la campana mayor.

\section{CONCLUSIONES}

Tras el análisis de la documentación y el estudio artístico del edificio hemos podido establecer las siguientes fases constructivas que afectan a la fábrica moderna (Figs. 11 y 12$)^{73}$.

En 1449 la familia de los Mariscales de Navarra elige San Pedro de la Rúa como panteón familiar: se construye el arcosolio en el lado norte del presbiterio.

En 1552 se abre la cripta de los Mariscales, realizada con sillería y bóveda rebajada, en el centro del presbiterio. Con los años esta circunstancia provocará un

$$
\begin{aligned}
& { }^{70} \text { Id., pp. } 165-166 . \\
& { }^{71} \text { Id., p. } 167 . \\
& 72 \text { Id., p. } 237 . \\
& 73 \text { Necesariamente complementarias a las con- }
\end{aligned}
$$
clusiones de nuestro anterior trabajo ( $\mathrm{M}^{\mathrm{a}} \mathrm{C}$. MUÑOZ PÁRRAGA y Mำ T. LÓPEZ DE GUEREÑO SANZ, “Las fábricas medievales...", pp. 46-47). larguísimo pleito por la propiedad y uso del mismo entre los mariscales y los parroquianos de San Pedro.

En 1572 se derriba el castillo que se alzaba sobre la peña, lo que provocará daños importantísimos en las cubiertas de la iglesia y también en el claustro.

Entre 1579 y 1678 los parroquianos de San Pedro de la Rúa y los Mariscales de Navarra y Marqueses de Cortes se enfrentan en un pleito sobre la propiedad de la capilla mayor de la iglesia, que tendrá importantes consecuencias en la fábrica del edificio.

Después de numerosos informes solicitados por los litigantes en el pleito, en 1609 , se desmonta la bóveda de la nave central por amenazar ruina.

En 1611 Juan de Larrañaga se compromete a renovar el tejado de la iglesia a cuatro vertientes.

A lo largo del siglo XVII se tienen que reforzar los pilares de la nave central y se colocan los tirantes o "arcos del miedo" para entibar los soportes.

En 1731 se realiza la bóveda de lunetos para cubrir la nave central, rebajando considerablemente la altura original. Todavía se pueden ver las partes altas de los soportes y los capiteles góticos desde el trasdós de la bóveda.

\section{APÉNDICE DOCUMENTAL}

1. “Obras del tejado de la iglesia 16011611. Declaración de tres oficiales canteros del riesgo en que está la Iglesia y que necesita de rebajarse".

\section{ARCHIVO PARROQUIAL DE SAN PE- DRO DE LA RÚA (ARCHIVO DIOCE- SANO DE PAMPLONA), CAJA 47 bis}

En la ciudad de Stella a cinco días del mes de mayo de mill seiscientos y un años 
Juan de Aguirre, vezino de la villa del arraga y domingo de olariaga vezino de ydiaçabal y julian fernandez vezino del lugar de Baquedano del valle de amescoa, maestros canteros y dixeron que apidimiento delos mayordomos y procuradores dela parroquial de san Pedro dela rua dela dicha ciudad, an visto y rreconozido la nave y partes necesarias que a abido de ver y rreconozer del sentimiento que seaecho en la dicha nave y yglesia y del daño que se alla y delo quees necesario para su rreparo y conserbación y bisto y rreconocido ocularmente dixeron que para abaxar las capillas altas y el tejado y paredes dela dicha iglesia como conbiene y en buena proporcion mirando toda la iglesia por dentro y fuera y encima las capillas della y la torre con todo lo demás que berse debía y que allan que las paredes dela dicha iglesia están sentidas y rrequebracadas por las grandes antiguas [tachado] paredes antiguas y cargadas que en ellas hay y les pareze a todos tres unánimes y conformes que se baxen las paredes dela dicha iglesia con sus tres capillas hasta en par de la cavecera de la dicha iglesia de manera que queden las dichas capillas bien proporcionadas y buenas y para esto an tasado la costa que puede tener las capillas y tejado y las dos paredes y el caracol questa enizia el calostro y la costa que an de tener de bajarse todo esto y los andamios y el hazerlos con la compra dela madera y cimbrias y hacerlos para deshazer y baxarlas con toda la costa que en lo suso dicho se ofrece les a parecido y les parece que terna de costa quinientos ducados ansi en hazer los dichos andamios y baxar el tejado y las tres capillas y paredes y caracol como esta dicho. Ecepto un pedazo cerca de la torre que esta apegado a ella, que llega a una bentana grande el qual dizen que se quede sin deshacer a tento esta apegado ala dicha torre y se quede para refuerzo della. Y lo demás sedes barate hasta el fundamento de la dicha bentana questa encima dela puerta que esta en el cuerpo de la dicha yglesia, y que lo dicho les a parecido y pareze so cargo de sus conciencias y esta declaración hicieron en presencia de Ffermin de Arellano escribano real mayordomo dela dicha yglesia que por si y en nombre de juan lopez ceran su compañero y los demás diputados dela dicha yglesia dio y pago alos dichos maestros por lo suso dicho treinta y ocho rreales y les acontento con ellos aunque pidian mucho mas y delo pagado doy fe yo celedon gomez escribano real y que ante mi lo declararon siendo presentes.

Por testigos Josephe de Heredia y Damian de Mendia, naturales de la dicha ciudad y firmo el dicho maestro Juan de Aguirre con el un testigo y el dicho fermin de arellano que los demás no saven escribir. En el registro del qual yo el dicho escribano saque esta engrosa en que fize este mi signo acostumbrado Juan de Aguirre, Joseph de Heredia, Fermin de Arellano, passo ante mi celedon gomez escribano.

2. “Obras del tejado de la iglesia 16011611. Poder otorgado por los mayordomos y diputados de la higlesia mayor de la ciudad de sobre el daño de la iglesia, 1606".

\section{ARCHIVO PARROQUIAL DE SAN PE- DRO DE LA RÚA (ARCHIVO DIOCE- SANO DE PAMPLONA), CAJA 47 bis.}

En la ciudad de Stella y capilla de la sanctisima Trinidad de la higlesia mayor de sant pedro de la dicha Ciudad a veynte y nuebe días del mes de Enero del año de mil seiscientos y seys.

Juntados en su diputación y parrochia conforme al uso y costumbre inmemorial que tienen los señores mayordomos y diputados de la dicha higla ques en Juan de Bearny y Sanguesa y mathias de urra, mayordomos, diego de san Xrobal, Juan de Reynalde y Juan belez diputados que son los que actualmente hacen y representan la dicha parrochia los quales dixeron que por horden de los mayordomos de la dicha parrochia el año ultimo pasado de mil seyscientos y uno Juan de Aguirre vecino de la villa Larraga y 
domingo de Olariaga vezino en ydiaçabal y julian fernandez vezino del lugar de Vaquedano dela balle de amescoa, maestros canteros vieron y reconocieron las naves y partes necesarias que havido que ver y reconocer del sentimiento que a echo en la dicha nave e higlesia y del daño que se alla y de cómo es necesario que con brevedad se ponga el remedio e hicieren relación que la nave de la dicha higlesia esta muy sentida y requebraçada por las grandes paredes y antiguas y cargadas que en ellas hay y que para el reparo y seguro de la dicha higlesia terna de costa mas de quinientos ducados como parece mas a largo del dicho auto de relación que paso por ante celedon gomez escribano real dela data en cinco del mes de mayo del dicho año de seyscientos y uno, que dan aquí por inserto y por quanto habiéndose comunicado trata de cómo se puede atajar tan grande daño como puede suceder con la Ruina y peligro en que esta la dicha higlesia atento que la dicha higlesia suplidos los gastos heredados no tiene con que poder hacer la dicha obra porque se entiende costara mucho mas dinero que los dichos quynientos ducados que los dichos canteros hacen relación porque se pretende hacer las capillas de la nave de la dicha higlesia todas ellas de ladrillo para que estén mas aliviadas las paredes de la dicha Iglesia con que quedara segura la dicha higlesia y para ello en conformidad han determinado de pedir licencia y permiso al señor vicario general deste obispado de pamplona para que puedan tomar los dichos mayordomos y diputados o Mayor parte de ellos los dichos quinientos ducados atento al quitar sobre las rentas y bienes en la dicha higlesia y obligar aquellos y otorgar escritura con las obligaciones y condiciones que conbengan y sea necesario y sin que por esto sea bisto perjudicar al derecho de patronos merolaycos ${ }^{74}$ que son los dichos constituyentes y sus subcesores en los dichos oficios y ala costumbre inmemorial en que están los dichos constituyentes de hacer y mandar

\footnotetext{
${ }^{74} \mathrm{~A}$ los que, generalmente, les solía corresponder el derecho de conceder títulos y licencias de sepultura dentro de la misma iglesia.
}

hacer todas las obras y reparos quese ofrecen hacer en la dicha iglesia sin que para ellos sea necesario licencia del señor obispo ni de su vicario general ni de sus visitadores y sin perjuicio desto ni de otras cosas que del pleito y lite que pende ante el probisor del obispado de Calaorra en grado de apelacion contra el fiscal deste obispado y con esta limitacion y no con otras en la mejor via, modo, forma y manera a que de derecho ha lugar dan y otorgan todo su poder cumplido y bastante a martin de Berrio prior en la curia eclesiastica y a los demás priores que usan de procuracion en las dichas audiencias a cada uno y cualquiera dellos de por si et insolidum Para que en nombre de los constituyentes con las dichas limitaciones y sin perjuicio del derecho dicho puedan pedir la dicha Licencia y permiso arriba Referido que todo lo quel y sus sustituidos hicieren y otorgaren la dicha Raçon habran por bueno Rato grato fiel y baledero, a ello obligaran los bienes y Rentas de la dicha higlesia havidos y por haver y que los relebaran de toda carga de satisfacion y enmienda estarán a justicia y pagaran lo juzgado renunciando su fuero $y$ juez y a mi el dicho Rogaran y Requeriran aga auto de ello e yo lo hice ansy a todo lo qual fueron presentes por testigos Lope de Rien y Juan de Areayn vecinos de la dicha Ciudad y los otorgantes a quienes doy fe conozco lo firmaron ante mi el escribano Juan de Bearin y Sanguesa, matias de urra, diego de sanxrobal, Juan de Reynalde, Juan belaz paso ante mi Gregorio de Mendico escribano por tanto signe firme et cerre.

En testimonio de verdad Gregorio de Mendico, escribano.

3. "Traza y condiciones de la obra del tejado de la iglesia".

\section{ARCHIVO PARROQUIAL DE SAN PE- DRO DE LA RÚA (ARCHIVO DIOCE- SANO DE PAMPLONA), CAJA 47 bis.}

Digo yo Joan de Larrañaga albañil que are la obra del tejado de la iglesia del 
señor san pedro por la horden, traza y condiciones siguientes.

Primeramente digo que hare la hobra del dicho tejado conforme a la traza que tengo dada la qual esta aprobada por oficiales peritos en el arte sin salir della en quanto a la forma y modo que esta trazada y explicada por letra acepto por que agora sea determinado seasiente la texa sin lodo por este respecto sea de baxar el cartabón que estaba de quatro partes del ancho de la Iglesia a una y agora sea de hazer lo que aca se usa quedándole de seis partes una y algo mas que será suficiente el pendente que tendrá para el dicho thejado y en quanto al grosor de las tablas será lo que al margen ba señalado que tanbien bastara que no ha de yr con lodos.

$\mathrm{Y}$ asi bien los cayrenes ${ }^{75}$ ternan de grueso lo que la traza dize y en quanto a la altura ternan una onza menos que la quarta que esta señalada y los dichos cayrones serán y me obligo a hacerlos de sezenas hechas quartos como por la traza se dize salvo la dicha onza menos y los dichos cayrenes yran repartidos en esta forma: tres en dos baras de medir y sin espacio que bernan ha hazer los anchos y claros dos pies y quarta de pie que con los gruesos de los dichos cayrones se llevaran las dos baras que los demás cayrones que fueren [....] arcos que yran arrimados a los aguilones porque an de aser mas cortos serán de catorcena si bien hechos quartos del mismo grosos y altor que los demás arriba referidos, esto en quanto alo que llegaren los dichos aguilones que todo lo demás restante heran como esta dicho con buenos cayrones de sezenos.

Ansi bien digo que ansi que por la relación de mi traza digo se macizen las ventanas atal no me obligo porque con poco dinero no se puede hazer mucha obra y amas de esto no ynporta se mazizen o se dexen de mazizarse solo les hechare unos cabezales

75 "Cairón": pieza de madera escuadrada que se coloca transversalmente a las vigas del techo, sobre la que se clavan los listones (J.M. IRIBARREN, Vocabulario navarro..., p. 88) para que sobre ellos cargue el dicho Tejado. Que la dicha obra del dicho Tejado la are buena y perfecta y bien acabada conforme mi dicha traza ecepto. En lo que adbierto y ecepto por este cartel que no me obligo a ello solo a sustentarla por tiempo y espacio de tres años contaderos aquellos del dia que quedare acabada de todo la dicha obra y tejado y en caso que hubiere algún bicio o se señalare algún defecto me obligo a remediarlo y obligare con mi persona y vienes $\mathrm{y}$ dare mis fiadores a ponerlo en su debida perfeccion como no sea por goteras ni falta de las paredes que acaso las tuviere sea a quenta de la Iglesia, y acabada la dicha obra y tejado se bea y reconozca por parte de la dicha Iglesia nombrando persona para ello que a una con la que yo de mi parte nombrare ayan de ver juzgar y reconocer si esta conforme la dicha traza y este cartel haciendo la dicha declaración con juramento ante el señor alcalde desta ciudad y estado como debe se pase por ella y si ubiere que enmendar se enmienda como lo hare a mi propia costa y a ello sea compelido o que lo hagan hazer por quenta mia y de mis fiadores los señores mayordomos. Toda la madera que se ubiere de gastar en este tejado será toda ella de pino fino o abete hasta los cabezales siendo como será sana, buena y perfecta y no de otra calidad y los dichos señores mayordomos la puedan hazer ber y reconozer asi que se asiente la dicha obra a costa de los dichos mayordomos y quando se ubiere de ber y bisitar sea allandome presente. Que la fianza que diere para el cumplimiento de la dicha obra y que se ara conforme a su dicha traza y su cartel eceptado lo que por el se ecepta la dara abonada por la justicia para el descargo de los dichos mayordomos y su seguridad.

Que hare la dicha obra del dicho tejado por trescientos y quarenta ducados como era tratado en esta manera: docientos ducados en dinero y de contado luego que hiziere escritura y dare la dicha fianza abonada para Justizia y tomar a su quenta los quatro maderos grandes que la Iglesia tiene comprados por sesenta ducados y los tayre a mi costa a esta ciudad de santa cara y 
sacare del rio a donde se me entregaran y los ochenta ducados restantes se me an de pagar los quarenta dellos luego que fuese acabada y reconozida la dicha obra y los otros quarenta ducados de allí en un año del dicho Reconocimiento y su declaración.

Que en reçeviendo los dichos ducientos ducados me partire a comprar toda la madera necessaria y comprada la are portear y traer a esta dicha ciudad y se serraran todas las tablas y cayrones necessarios para la dicha obra y Pondre todo los demás necessario apunto para que con ayuda de los Parrochianos se pueda subir a la dicha Yglessia de señor san pedro y poner en el cuerpo de ella a la parte donde yo señalare y esto estará todo apunto y aparejado dentro de tres meses de la fecha de la escritura de manera que quando se me entreguen los dichos quatro maderos este como estará todo a la mano sin que falte cossa ninguna de materiales. Que estos seme ayan de dar para fin de Jullio y no entregándomelos en el dicho vocar de santa cara no este obligado por este año a hacer la dicha obra por que en ynbierno nose podrá travajar en ella. Pero entregándomelos por todo el dicho mes o antes la are en su devida perficion dentro de tres meses sin otro plaço alguno.

Que seme aya de dar y de toda la texa Vieja que esta dentro de la dicha yglessia con la piedra que tuviere necessidad para recalçar cafixar la dicha obra de gracia e sin ynteresses alguno y Puesta toda la madera al pie de la escalera de San Pedro que me la ayan de subir los Parrochianos de la dicha Yglessia al cuerpo de ella como queda dicho sin estar obligado a pagarles cossa alguna. Y no este obligado a maçiçar las ventanas aunque en mi traça lo digo. Pues con poco dinero nose puede haçer mucha obra ni atal me obligo, cierto que hechare sobre ellas sus caveçales para que sobre ellos cargue el dicho texado. Y en todo lo demás cumpliré con el tenor de la dicha traça y con lo que por este cartel refiero aceptando. Lo que saco y acepto de ella y la executare y a ello me obligare con mi persona y Vienes y los demás fiadores y are escritura en forma de todo lo que digo y refiero.

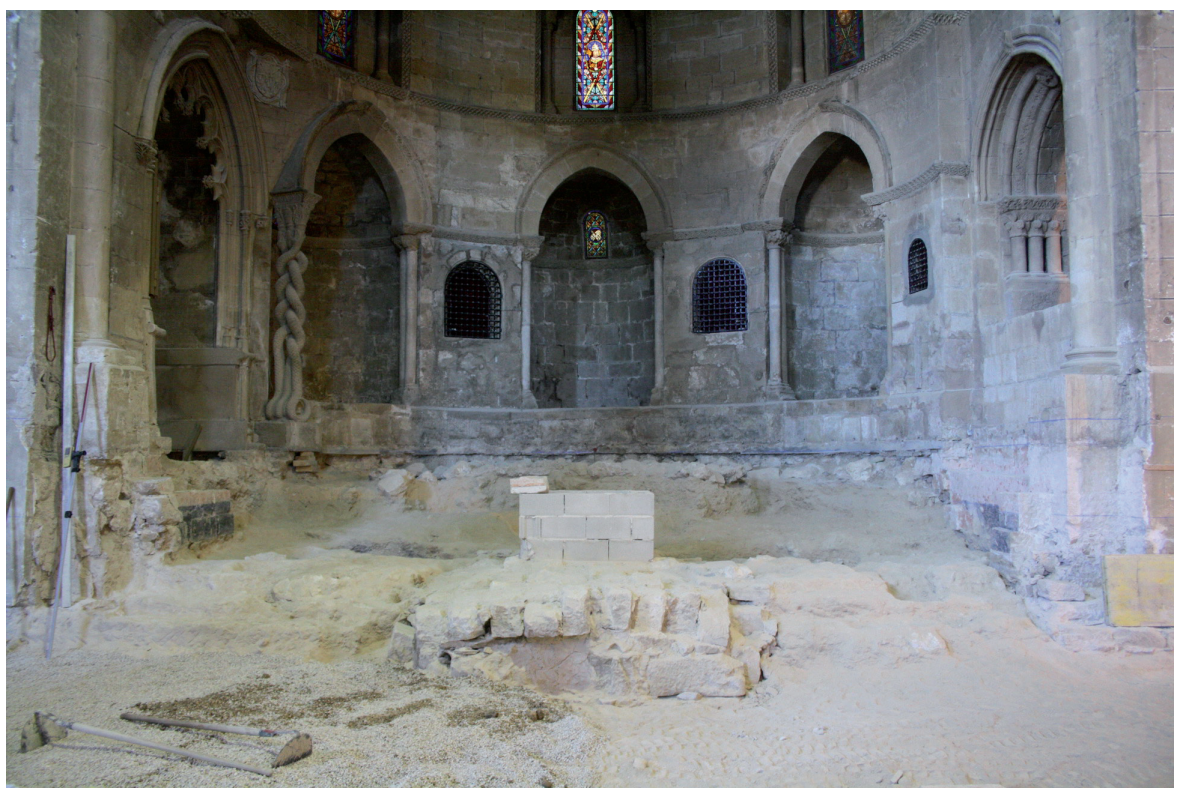

- Fig.1. San Pedro de la Rúa. Vista del presbiterio durante las excavaciones. 


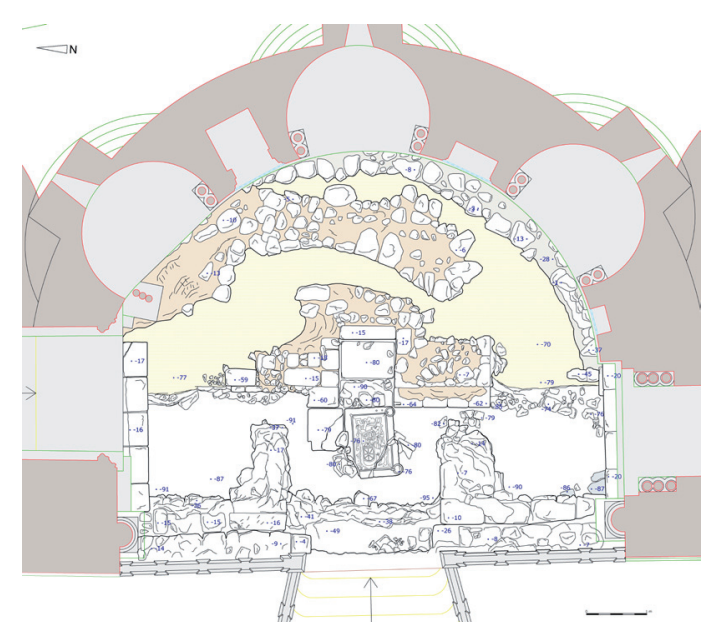

- Fig.2. San Pedro de la Rúa. Planta del presbiterio a partir de de las excavaciones (STRATO).

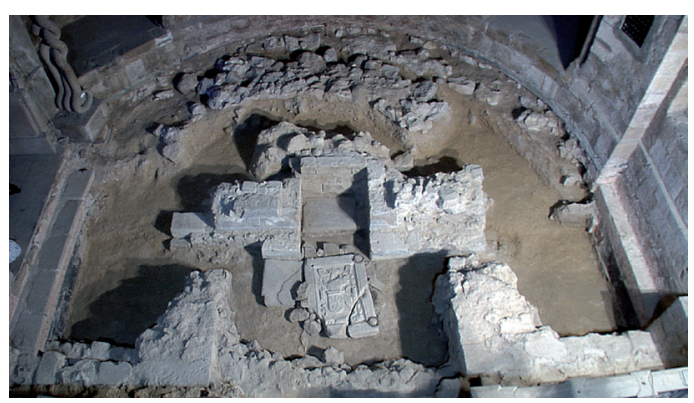

- Fig.4. San Pedro de la Rúa. Cripta de los Mariscales de Navarra durante las excavaciones.
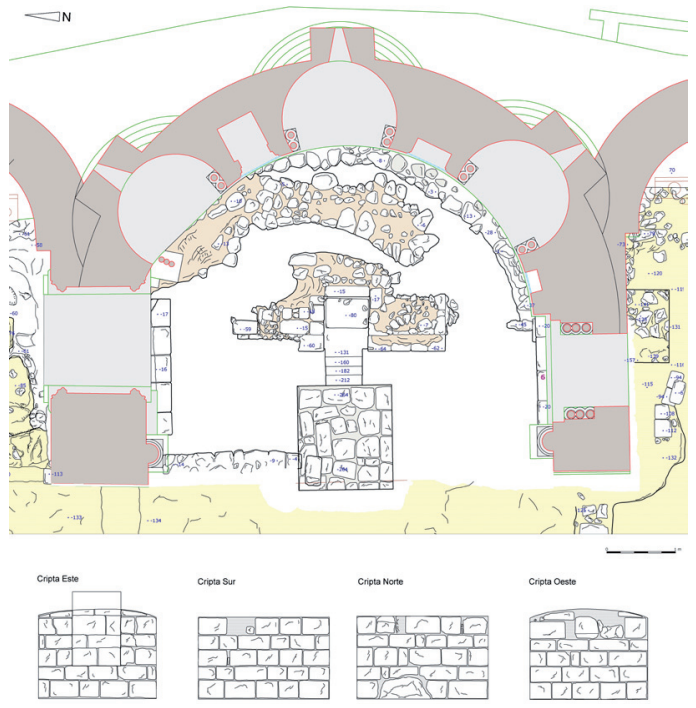

- Fig.6. San Pedro de la Rúa. Planta y secciones de la cripta de los Mariscales de Navarra (STRATO).

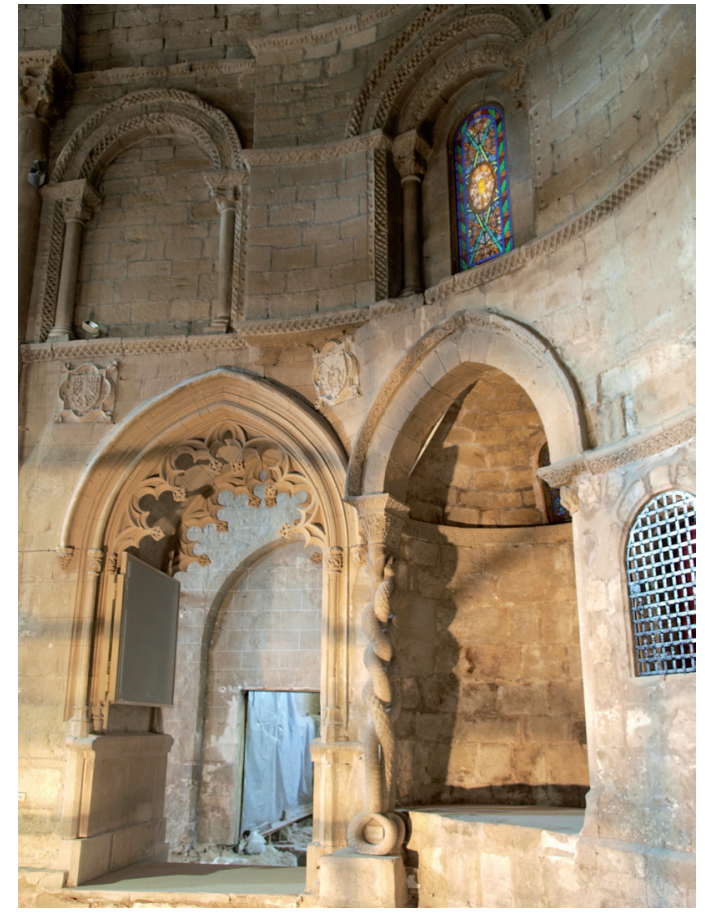

- Fig.3. San Pedro de la Rúa. Arcosolio de los Mariscales de Navarra, en el lado del Evangelio del presbiterio.

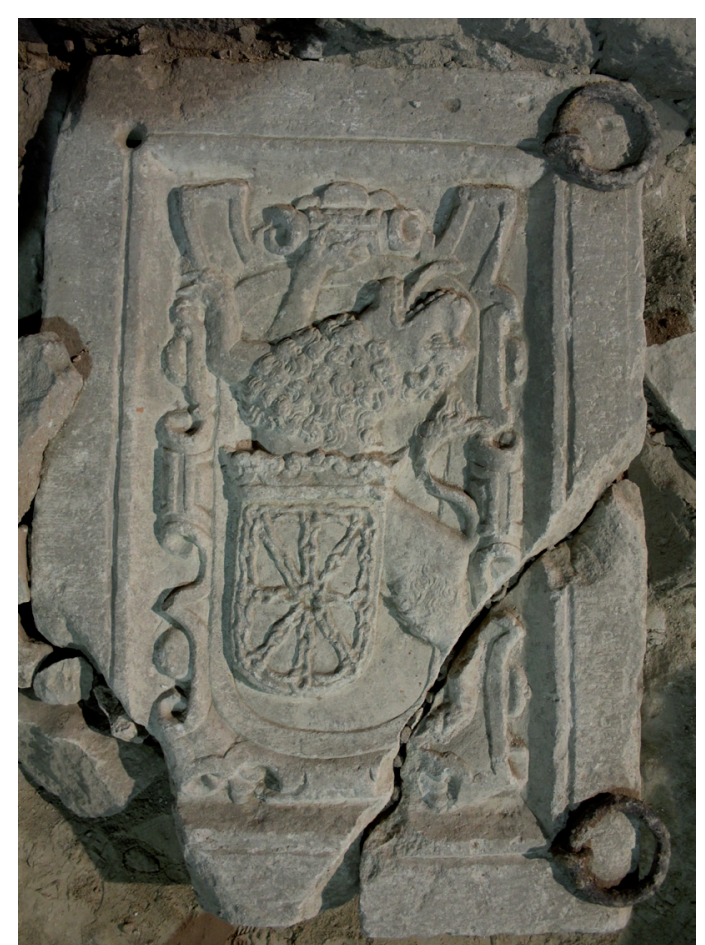

- Fig.5. San Pedro de la Rúa. Lauda sepulcral que cubría la entrada de la cripta de los Mariscales de Navarra. 


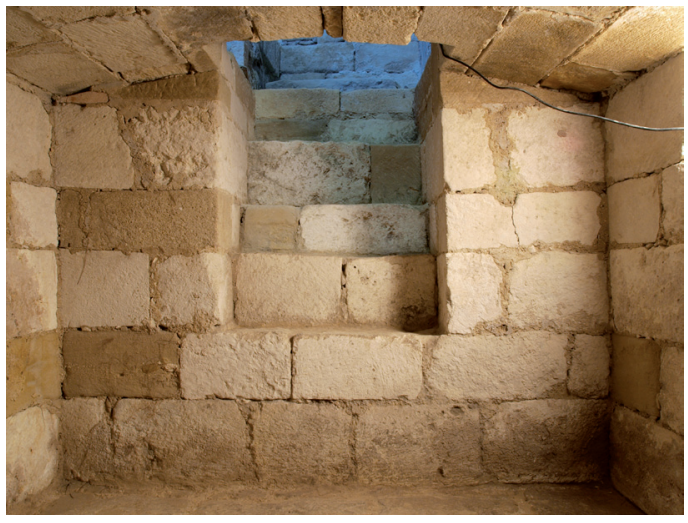

- Fig.7. San Pedro de la Rúa. Interior de la cripta de los Mariscales de Navarra.

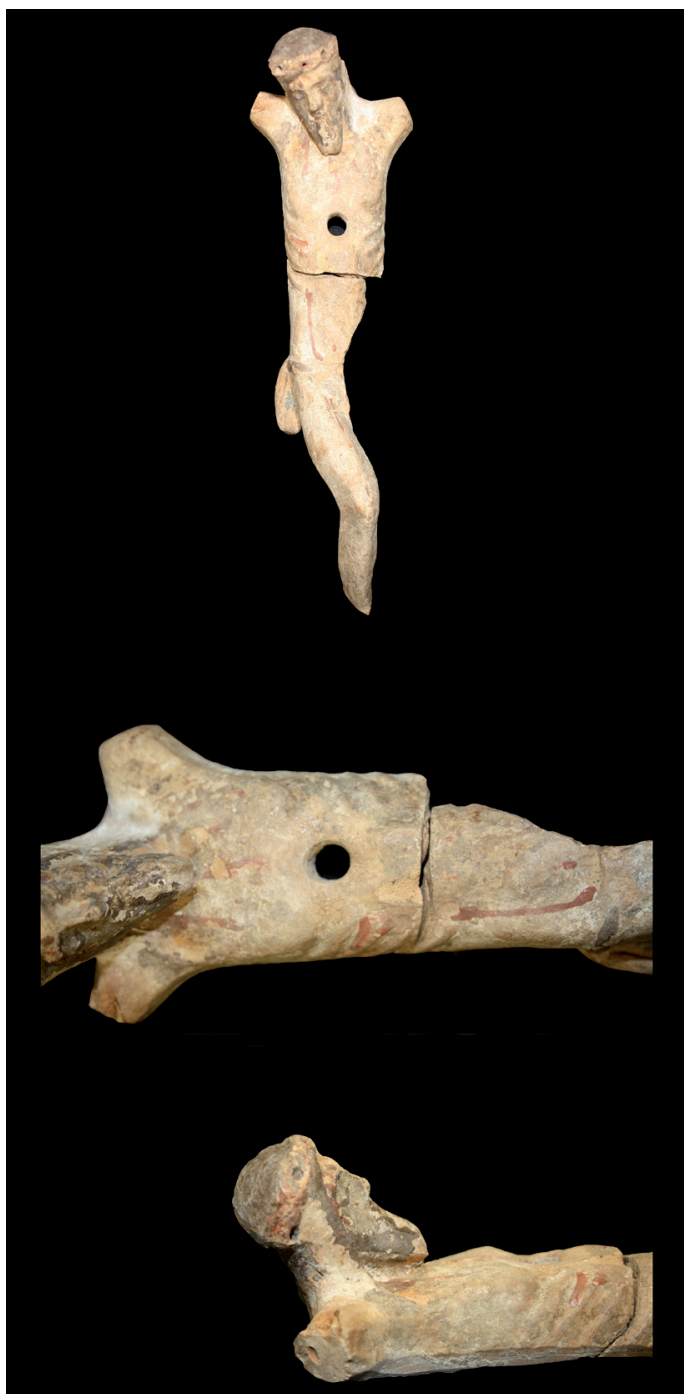

- Fig.9. San Pedro de la Rúa. Cristo hallado en el interior de la cripta de los Mariscales de Navarra (STRATO).
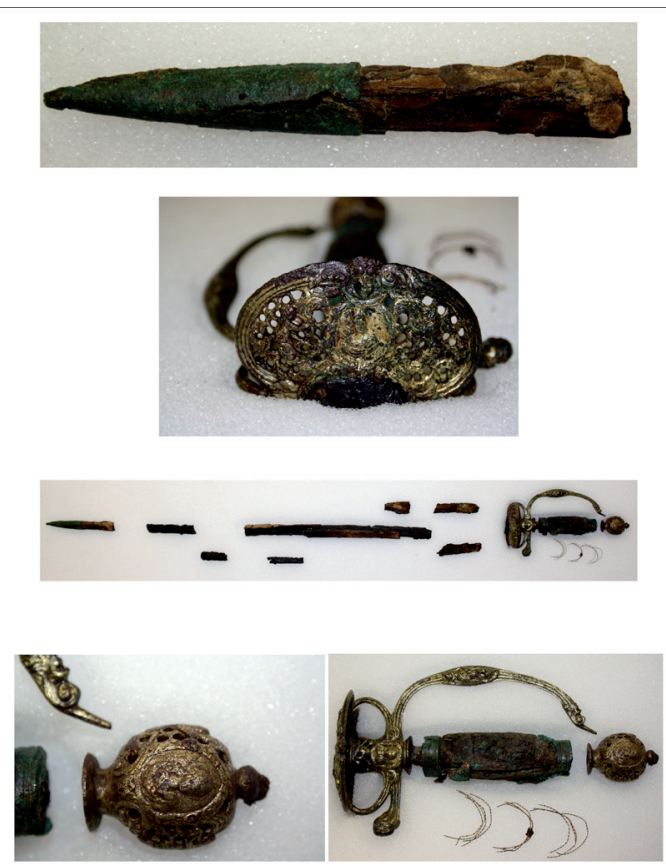

- Fig.8. San Pedro de la Rúa. Espada hallada en el interior de la cripta de los Mariscales de Navarra (STRATO).

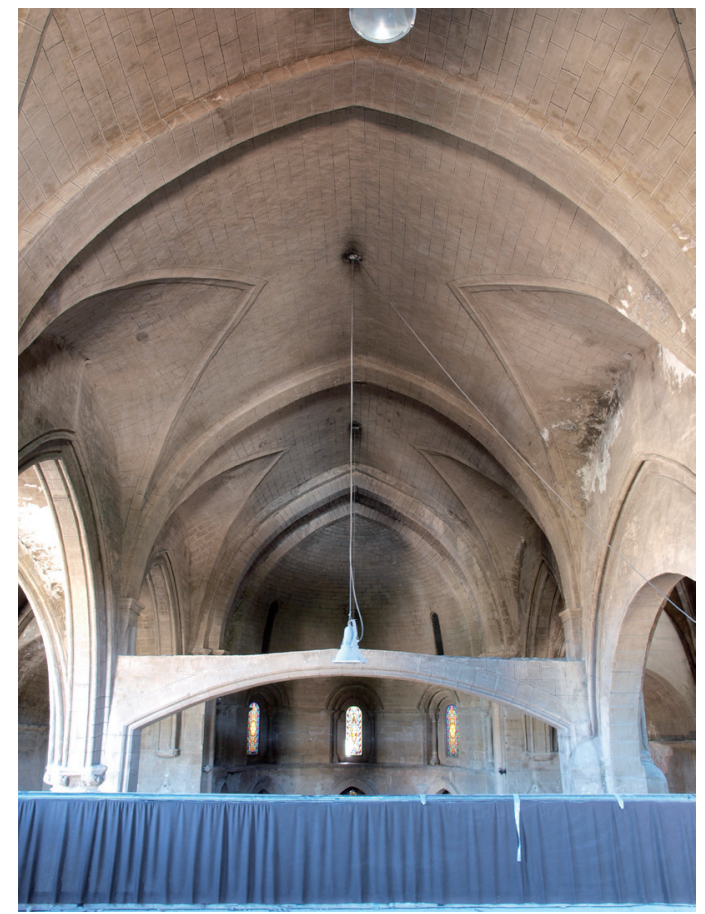

- Fig.10. San Pedro de la Rúa. Bóveda de la nave central y "arco del miedo" antes de la restauración del templo. 


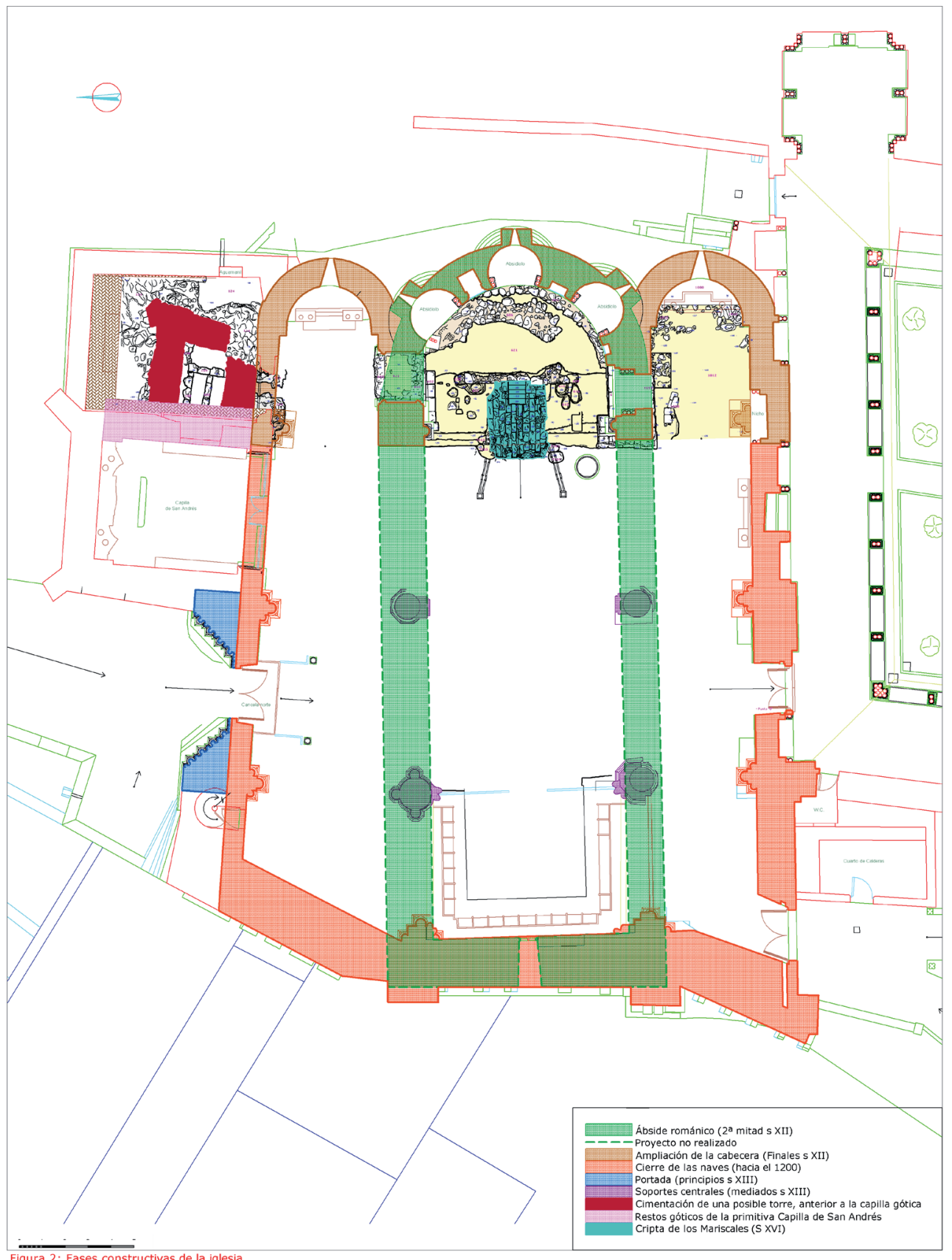

- Fig.11. San Pedro de la Rúa. Fases constructivas de la iglesia (con la cripta de los Mariscales de Navarra en verde intenso), según Muñoz Párraga y López de Guereño Sanz (sobre plano elaborado por la Institución Príncipe de Viana). 


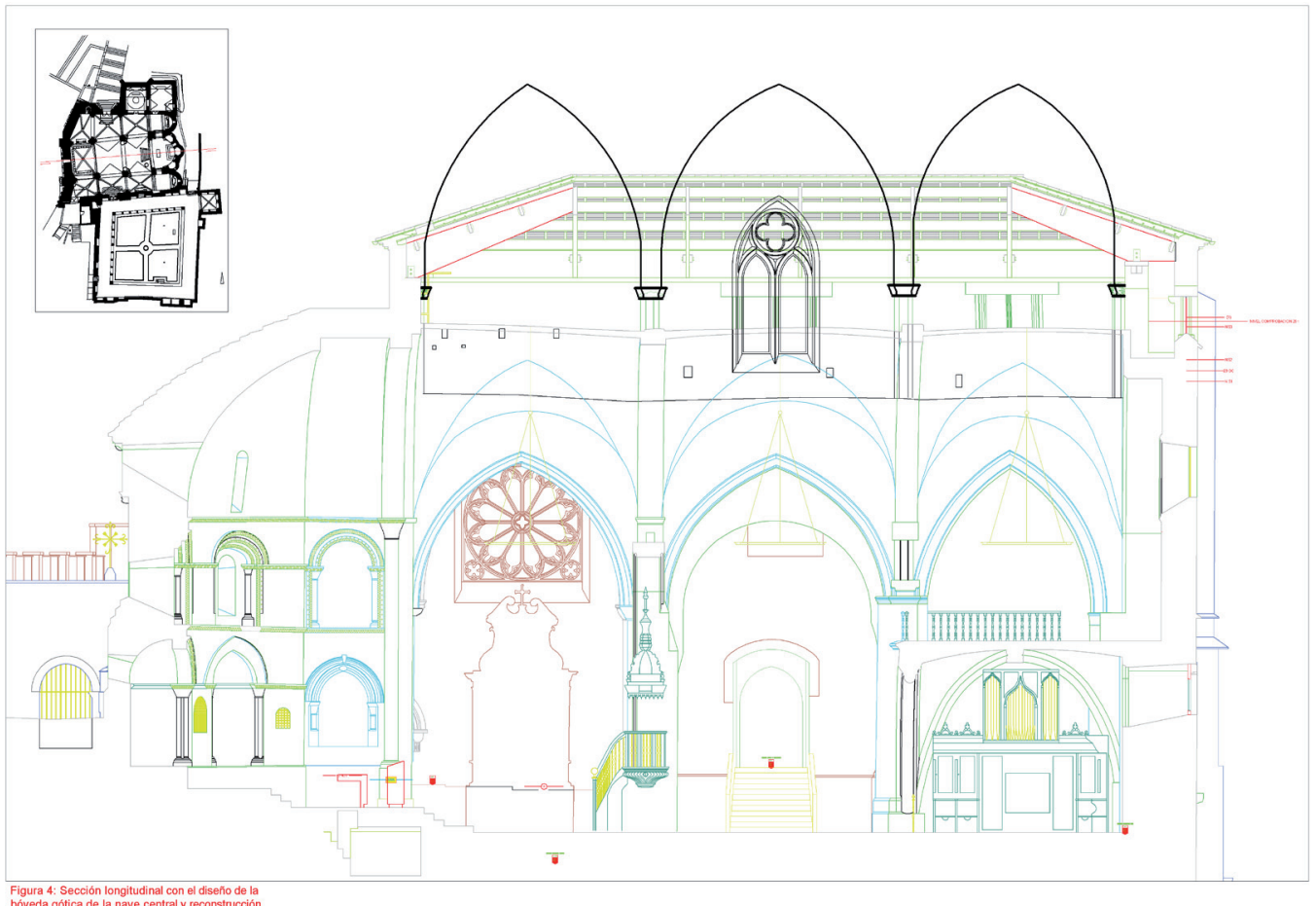

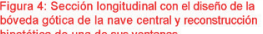

- Fig.12. San Pedro de la Rúa. Sección de la iglesia con las bóvedas original y actual de la nave central y la cripta de los Mariscales de Navarra, según Muñoz Párraga y López de Guereño Sanz (sobre plano elaborado por la Institución Príncipe de Viana). 